\title{
A Comprehensive Review of the Development of Carbohydrate Macromolecules and Copper Oxide Nanocomposite Films in Food Nanopackaging
}

\author{
Mohammad Mesgari, ${ }^{1}$ Amir Hossein Aalami, ${ }^{2}$ Thozhukat Sathyapalan, ${ }^{3}$ \\ and Amirhossein Sahebkar (iD) $4,5,6,7$ \\ ${ }^{1}$ Department of Food Science and Technology, Faculty of Agriculture, Ferdowsi University of Mashhad, Mashhad, Iran \\ ${ }^{2}$ Department of Biology, Mashhad Branch, Islamic Azad University, Mashhad, Iran \\ ${ }^{3}$ Department of Academic Diabetes, Endocrinology and Metabolism, Hull York Medical School, University of Hull, Hull, UK \\ ${ }^{4}$ Biotechnology Research Center, Pharmaceutical Technology Institute, Mashhad University of Medical Sciences, Mashhad, Iran \\ ${ }^{5}$ Applied Biomedical Research Center, Mashhad University of Medical Sciences, Mashhad, Iran \\ ${ }^{6}$ Department of Medical Biotechnology and Nanotechnology, Faculty of Medicine, Mashhad University of Medical Sciences, \\ Mashhad, Iran \\ ${ }^{7}$ Department of Biotechnology, School of Pharmacy, Mashhad University of Medical Sciences, Mashhad, Iran
}

Correspondence should be addressed to Amirhossein Sahebkar; amir_saheb2000@yahoo.com

Received 25 October 2021; Accepted 7 February 2022; Published 5 March 2022

Academic Editor: Guillermo Mendoza-Diaz

Copyright (C) 2022 Mohammad Mesgari et al. This is an open access article distributed under the Creative Commons Attribution License, which permits unrestricted use, distribution, and reproduction in any medium, provided the original work is properly cited.

\begin{abstract}
Background. Food nanopackaging helps maintain food quality against physical, chemical, and storage instability factors. Copper oxide nanoparticles (CuONPs) can improve biopolymers' mechanical features and barrier properties. This will lead to antimicrobial and antioxidant activities in food packaging to extend the shelf life. Scope and Approach. Edible coatings based on carbohydrate biopolymers have improved the quality of packaging. Several studies have addressed the role of carbohydrate biopolymers and incorporated nanoparticles to enhance food packets' quality as active nanopackaging. Combined with nanoparticles, these biopolymers create film coatings with an excellent barrier property against transmissions of gases such as $\mathrm{O}_{2}$ and $\mathrm{CO}_{2}$. Key Findings and Conclusions. This review describes the CuO-biopolymer composites, including chitosan, agar, cellulose, carboxymethylcellulose, cellulose nanowhiskers, carrageenan, alginate, starch, and polylactic acid, as food packaging films. Here, we reviewed different fabrication techniques of $\mathrm{CuO}$ biocomposites and the impact of CuONPs on the physical, mechanical, barrier, thermal stability, antioxidant, and antimicrobial properties of carbohydrate-based films.
\end{abstract}

\section{Introduction}

Plastic is a hazardous material and very challenging to decompose, one of the world's fundamental problems. The use of plastic has a role in ordinary life, particularly food packing and different accessories $[1,2]$. About $63 \%$ of the current plastic waste comes from packaging purposes, and it is calculated that less than $14 \%$ is recyclable [3]. Recently, there is a more significant interest in using sustainable and degradable packaging, as they are usually functional and more environmentally friendly [2]. Therefore, there is a growing requirement for bio-based natural materials to resolve the waste disposal problems to an ensured magnitude. In this regard, biopolymers, especially those from renewable nonchemical resources, have been considered replacements of nonbiodegradable plastic supplies $[4,5]$.

Biopolymers are natural, environmentally friendly, nontoxic, and a real option to decrease nonbiodegradable and nonrenewable materials in the packaging productions 
$[6,7]$. Proteins, polysaccharides, and lipids are the most common biopolymers utilized in the packaging materials [8]. Active food packaging (AFP) with natural antimicrobial agents is a suitable prospect for extending food products' shelf life, including fruit, meat, fish, and bread packaging [9]. To achieve active nanopackaging, degradable films have been combined from functional additives such as antioxidants and antimicrobials agents that may be transferred from packaging to food products to extend their shelf life $[6,10,11]$. Antioxidant-containing films could primarily prevent the oxidation of fatty foods [12].

Nanotechnology-arisen products are now used in numerous fields of life and have shown their potential from industry to basic sciences and medicine to develop new tools, systems, and drugs $[13,14]$. Metallic nanoparticles (MNPs) synthesized by multiple unique methods and properties, which help their exploitation in independent fields, such as nanodiagnostics $[15,16]$, nanomedicine [17-19], antibacterial [19-21], antioxidant $[19,20,22,23]$, luminescence $[24,25]$, photocatalytic $[24,26]$, painting, ceramic, glass production, and food packaging industry [27-34]. Nanoparticles such as titanium, silver, zinc, and copper have been applied worldwide to form nanocomposite packaging materials with antimicrobial and antioxidant activities [7, 35-37].

The metal oxide nanostructure, especially copper oxide nanoparticles (CuONPs) structures, is interested in its potential importance in the biomedical field [38]. The CuONPs can inhibit the growth of microorganisms such as bacteria, fungi, viruses, and algae [39]. The size of nanoparticles and the high surface zone of $\mathrm{CuO}$ permit them to interact closely with the cell membrane and thus have an excellent antimicrobial potential $[40,41]$. Copper ions destroy them by receiving and donating electrons, revealing high redox potential and interrupting microbial cell components [42]. The antibacterial and antioxidant activities of CuONPs have been extensively studied in some fields, such as the improvement of polymer nanocomposites and food packaging materials $[43,44]$. The principal purpose of this review is to discuss the role of CuONPs in the active food packaging system. The food packaging biomaterials combined with CuONPs are classified by the polymer type used to fabricate food.

\section{Food Packaging}

The principal purpose of food packaging is to maintain the quality and protection of food products from unpleasant odors, preserve flavor, and also in storage, transportation and to increase their shelf life by protecting from hazardous microorganisms and their toxins, chemical composites, sunlight, temperature, permeable volatile compounds, oxygen, and humidity $[45,46]$. Alterations in packaging lead to quality packing and consumer-friendly access in managing the shelf life and biodegradable packing [47]. In this regard, biopolymers can be used as active food packaging or for food coverage purposes as biodegradable materials that participate in the cycle of nature, reducing environmental effects and oil dependency [48].

\section{Active Food Packaging}

Active food packaging films have been developed in recent years to increase the shelf life and protect the quality of food goods. Antioxidant activity in these types of active food films has mainly been focused on limiting or delaying lipid and protein oxidation. Unlike typical food packaging materials, active food packaging methods have adequate barriers against $\mathrm{H}_{2} \mathrm{O}$ and $\mathrm{O}_{2}$, humidity absorbers, flavor, carbon dioxide absorbers or emitters, ethylene gas (such as ethylene absorbers/oxidizing agents), antioxidation materials, and antimicrobial agents [49-54]. Depending on the functional elements set in the biopolymers, the packaging can offer biological activities for the packaged foods, such as antioxidant and antimicrobial shields [55]. In this regard, some nanoparticles, such as copper oxide nanoparticles, have been exploited as active nanostructured food packaging materials with the association of some macromolecule biopolymers [56-61]. In the following sections, important biopolymers in food packaging, the barrier features of the food packaging process, and their mechanical properties are summarily explained with particular attention to CuONPs in food packaging, antimicrobial, and antioxidant permeability.

3.1. Carbohydrate Polymers. Biopolymers originated from different natural sources such as polysaccharides, protein, or aliphatic polyesters (Table 1). They have been touted as intriguing alternatives to traditional polymers since they are renewable, self-sufficient, cost-effective, environmentally friendly, and biodegradable [62]. The carbohydrate polymers in food packaging supplies can be divided into several subgroups.

3.1.1. Agar. Agar is a linear polysaccharide consisting of $\beta-1$, 3 D-galactose, and $a$-1, 4-linked 3,6-anhydrous-L-galactose units with partial side-chain substituents such as sulfate ester, methoxyl group, and pyruvate [63, 64]. Agar is a fiber carbohydrate extracted from a group of seaweeds of the class Rhodophyceae. It is one of the most suitable materials because it is abundant, thermoplastic, biocompatible, and biodegradable [62]. Today, agar is widely used as a food packaging material due to its excellent film-forming ability, thermoplasticity, environmental adaptability, biodegradation, and water resistance. On the other hand, agar-based films have disadvantages in food packing, such as lowtemperature stability, restricted oxygen, and low water barrier qualities $[65,66]$.

3.1.2. Starch. Starch is a natural polysaccharide that performs essential functions in food production as high-quality components or additives. Structurally, starch is made of two macromolecules: amylose and amylopectin. Amylose is a linear polysaccharide, $\operatorname{poly}(\alpha-1,4$-glucopyranosyl), whereas amylopectin is poly ( $\alpha-1,4$-glucopyranosyl) with many $a-1$, 6-glucopyranosyl branches [67, 68]. Starch-based films are among the most valuable classes of bio-based packaging material in terms of performance, adjustability to products, 
TABLE 1: Biodegradable polymers used in food packaging.

\begin{tabular}{lcc}
\hline Polysaccharides & Proteins & Aliphatic polyesters \\
\hline Agar & Collagen & Polylactic acid (PLA) \\
Alginate & Gelatin & Polyhydroxy butyrate (PHB) \\
Carrageenan & Whey protein & Soy protein \\
Cellulose & Zein & \\
Chitin/Chitosan & & \\
Curdlan & & \\
Gellan & & \\
Pectin & & \\
Pullulan & & \\
Starch & & \\
Xanthan & & \\
\hline
\end{tabular}

processing, and price [69]. The edible films from cereal and roots of starches have widely been developed and examined for their features. However, the studies on films created from legume starches are strangely limited [69]. Starch is commonly employed as an adhesive, additive, or thickening in food packaging. The benefit of starch is that it acts as a medium oil barrier. However, it may be faulty in a humid environment due to hydrophilic functional groups in molecule formation. Its crystalline region can form a parclose against external gases, which amylose films have a powerful impact than amylopectin films [70]. The starchbased film applied as a packaging material is too brittle. Starch independently cannot form edible films that possess the expected mechanical properties unless combined with bio-ingredients such as a bio-food package [71].

3.1.3. Cellulose. Cellulose is a natural polymer made from corncobs, which is environmentally friendly and biodegradable. Cellulose makes up roughly $40 \%-50 \%$ of the total content of natural fibers and alters the chemical features of fiber plants. Plants create around 75 billion tons of cellulose every year, resulting in fantastic cellulose biopolymers [72]. The usual cellulose formula is (C6H10O5)n, with cellulose as the significant component. Cellulose is rarely seen in nature in its purest form [73].

Moreover, colorants, gums, lipids, tannins, lignin, and hemicellulose are often mixed with cellulose. The 1,4-glycosidic bonds linking the cellulose and $\beta$-glucopyranoside residues are utilized to reveal cellulose's prime shape $[74,75]$. Because of their recyclability and degradability, cellulose nanocomposite films have gotten much attention. However, their high cost and susceptibility to water limit their use [70].

(1) Bacterial cellulose (BC) is a microbial polysaccharide biopolymer created by nanofibrils made mainly by Gluconacetobacter xylinus, Acetobacter hansenii. It has a similar chemical construction presented by plants [76]. BC has individual characteristics broadly used in medical, cosmetics, industrial, and electronic purposes, especially in biomedical science and food packaging, because its threedimensional nanofibrillar networks have excellent mechanical and barrier performance, water-holding ability, and structure-forming potential $[77,78]$. Bacterial cellulose has a unique construction of nanofibrils, making a nanostructured network characterized by high pureness (compared to plant cellulose, BC is free of elements such as hemicellulose and lignin) $[79,80]$. The biocompatibility, excellent crystalline features, high mechanical stability, and high-water absorption capacity in the wet state of $\mathrm{BC}$ can increase the strength of the biocomposite films. BC could also absorb moisture, increase $\mathrm{O}_{2}$ permeability and water vapor permeability (WVP), and the thermal stability of films. Furthermore, the United States Food and Drug Administration has classified BC as safe (GRAS) since 1992 [80-82]. In Asian nations, using "traditional" fermentation techniques, $\mathrm{BC}$ is constructed and sold as a high-fiber food and low-calorie dessert [83]. Overall, BC can be quickly prepared into nanofibrils, microfibrils, and nanocrystals and can be utilized to fabricate nanocomposite films [76]. Because bacterial cellulose nanofibers (BCNFs) have limited antibacterial and antioxidant activity, they are rarely used as a food packaging film or wound treatment [78].

(2) Carboxymethylcellulose (CMC), an anionic cellulose derivative, which because of its availability, cheap cost, biodegradability, hydrophilic, nontoxic, and renewable properties, has gained special attention for enhancing biobased films. CMC can be synthesized with the catalyzed cellulose reaction with monochloroacetic acid [84]. As an edible film and water-soluble polymer, it is extensively utilized in food processing as stabilizers and thickeners in different foods. It can create highly original and flexible biodegradable films with acceptable mechanical characteristics. It has also been given the label of "generally recognized as safe" (GRAS) [66]. CMC is a water-soluble cellulose derivative used as an additive in pharmaceutical and food applications. It has an essential role in fabricating many support materials for many enzymes such as isoamyl lactase, $a$-amylase, lipase, and polyphenol oxidase. Furthermore, $\mathrm{CMC}$ has been described as a valuable adsorbent to remove dyes, owing to the comparatively abundant carboxyl groups $[85,86]$.

(3) Cellulose nanowhiskers (CNWs) are usually obtained by hydrolysis techniques from natural cellulose-based materials such as bacteria, plants, and sea creatures. Its size varies from a few nanometers to several tens of nanometers in diameter and $100 \mathrm{~nm}$ [87]. CNW has been employed in the creation of advanced valuable materials for purposes such as biomedical, optical, structural, tissue engineering [88], drug delivery [89], energy storage [90], electronic 
devices [91], wastewater treatment [92,93], coating additives, molecular biology, paper production, cosmetics, composite materials [94,95], and food packaging [96,97]. CNWs have attracted attention because, as a nanostructure, they present low density, extensive surface area, high mechanical stability, high modulus of elasticity, low thermal extension coefficient, large aspect ratios, optical transparency, unique morphology, smooth of production, and chemical reactivity $[87,88,98-102]$. Several desired qualities of the CNW include abundance, repeatability, low density, low cost, considerable and varied surface area, biocompatibility, and biodegradability, which have seen much application in the polymer composite reinforcement [103]. When combined with polymeric film materials, cellulose nanowhiskers (CNWs) with high aspect ratios improve the film features [104]. These characteristics make it an excellent biopolymer to employ in the food packaging $[96,97]$.

3.1.4. Chitosan. Chitosan is a chitin-based polymer with a linear structure ordered by deacetylated and acetylated units [70]. After cellulose, chitosan is the second most abundant polysaccharide on the planet, and it may also be found in some fungal cell walls [105]. Chitosan gives an extensive range of purposes, including the purification of water and beverages, cosmetics and pharmaceuticals, biotechnological and agricultural applications, and food packaging [106]. Chitosan is nontoxic and biodegradable, and possesses several natural properties, including enhanced strength and elongation. On the one hand, chitosan films exhibit outstanding mechanical properties and selective permeability to gases $\left(\mathrm{CO}_{2}\right.$ and $\left.\mathrm{O}_{2}\right)$.

On the other hand, its hydrophilic nature has a poor moisture barrier, limiting its applications [107, 108]. The degree of deacetylation, the molecular weight, the number of acetyl groups on the main chain, and the kind of acid used for protonation all affected chitosan solubility due to the amino groups being soluble in weak acid solutions lower than $\mathrm{pH}$ 6.0, unlike chitin. Aside from solubility, chitosan's molecular weight might affect the film's quality, including optical properties, brittleness, and elasticity $[109,110]$. The USFDA has authorized chitosan as a food supplement [111]. Food safety against microbial deterioration, the creation of edible biodegradable films, condensation of proteins and lipids from wastewater, enhancing gelation in fisheries goods, and deacidification of fruit juice are only a few items for chitosan in the food applications [112]. Chitosan is an antibacterial biopolymer that may be used as an antimicrobial agent and a biopolymer substrate. Because of their superior antibacterial properties, chitosan films are acknowledged as eco-friendly food packaging. They have a long shelf life and keep food fresh [113]. Moreover, in contrast to water, in acidic solutions, it dissolves easily [70].

3.1.5. Polylactic Acid (PLA). Polylactic acid (PLA) is one of the most promising and environmentally friendly polymers due to its exceptional physical and chemical features: renewability, biodegradability, and biocompatibility. PLA is made from renewable sources such as maize starch (in the
United States and Canada), cassava roots or starch (in Asia), or sugar cane (in the rest of the globe) [114]. Corn-derived PLA is biodegradable, making it ideal for nutritional uses. According to the USFDA (United States Food and Drug Administration), the PLA has considered an entire safe status (GRAS) [115]. In 2010, PLA accounted for the enormous consumption volume globally compared to other bioplastics [116]. On the other hand, PLA has a significant permeability to gas and vapor, limiting its use in food packaging for short-term storage [117]. Given that PLA is nontoxic, noncarcinogenic, biocompatible, hydrophilicity, water-soluble, and chemically steady, it is typically combined with other polymers.

3.1.6. Xanthan Gum. Xanthan gum is a pentasaccharide. It is an extracellular heteropolysaccharide with high molecular weight created by Xanthomonas campestris [118, 119]. Xanthan gum consists of D-glucose, D-mannose, and Dglucuronic acid units and in the proportion of $2: 2: 1$ $[120,121]$. Approximately half of the terminal D-mannose is connected to pyruvyl residues. It has converted to one of the most effective hydrocolloids due to its high ability, especially in high salt, acid, and shear stress. It is steady over a broad $\mathrm{pH}$ range $[122,123]$. Xanthan is accepted as a food component by the USFDA [124]. Xanthomonas campestris is a Gram-negative aerobic rod bacterium that is one of the most lucrative industrial microbial hydrocolloids used as a thickening factor and stabilizer in the food preparation $[125,126]$. The mechanical characteristics and moisture adsorption of cassava starch films have been affected by the xanthan [127]. Xanthan gum has a pseudoplastic rheological performance in an aqueous environment employed in film production. It disperses well in water at any temperature, and $\mathrm{pH}$ or temperature does not affect its viscosity $[123,127]$. The xanthan gum boosted film traction stability but made the matrix less flexible. Xanthan is proper for food packaging because of its ability to adjust viscosity. However, more research is needed to see whether it can fully stand alone as a food packaging source [71]. Gelatin films combined with xanthan gum present a transparent film with extreme UV light resistance, low solubility, moisture content, low water vapor permeability (WVP), increased mechanical characteristics, and thermal stability [127]. Presently, mixing with different biopolymers is recommended to produce an excellent food package. The expensive production is another critical problem facing its production [71].

3.1.7. Gellan Gum (GG). Gellan gum (GG) is an anionic, water-soluble, high-molecular-weight, and deacylated exocellular polysaccharide that is secreted from bacteria belonging to the Sphingomonas genus and Sphingomonas paucimobilis (earlier Pseudomonas elodea) [128-131]. First isolated in 1979, these bacteria have a helix-forming and gelling ability produced as a fermentation product. GG is currently manufactured in vitro by a simple fermentation method, bypassing batch-to-batch availability associated with the biopolymers [132]. GG is made up of a repeated 
linear chain of tetrasaccharide units and consists of a linear chain of tetrasaccharide parts (L-rhamnose, D-glucose, and D-glucuronic acid) in a 3:1:1 molecular ratio, containing one carboxyl side group [120], commercially available under many trade names (e.g., Phytagel ${ }^{\mathrm{TM}}$, Gelrite ${ }^{\circledR}$, and Kelcogel $\left.^{\circledast}\right)$ [128, 132, 133]. After FDA approval as a food additive in 1992, this polysaccharide is extensively exploited in the food industry as a thickening factor or emulsion stabilizer to improve food quality [129, 132, 134]. Gellan gum hydrogel films, because of the biocompatibility and low cytotoxicity, has widespread use in pharmacology (implant for insulin delivery, and nasal and ophthalmic drug delivery agent), cell carrier, an anti-adhesion barrier, a guided boneregeneration material, tissue engineering, and wound dressing materials $[129,135,136]$. Polymer negative groups interact with divalent or multivalent counter ions to form a more substantial, thick hydrogel network. GG shows unique film-forming, biodegradable, biocompatible features, as well as an excellent drug release kinetics [128]. The gelation conditions bring about a wide diversity of textures and mechanical properties [135]. Furthermore, gellan gum is in the coil form at high temperatures or in acid circumstances, presenting higher heat and acid stability for active compounds and probiotics [128].

3.2. Carbohydrate Polymers Based on CuONPs in Food Packaging. Many researchers have employed silver, zinc oxide, and titanium dioxide nanoparticles to increase the water vapor barrier, mechanical properties, and antibacterial properties of films [137-140]. In addition to these nanoparticles, copper oxide nanoparticles (CuONPs) have attracted researchers due to their novel features such as a high surface-to-volume ratio, barrier to visible and UV light, low water vapor preliminary, cheaper element compared to other nanoparticles, increased mechanical characteristics in synthetic polymers, and nontoxicity $[141,142]$.

With the decrease in size, the CuONP properties increase, and finely dispersed bioactive CuONPs are predicted to have a significant disinfectant action [143]. Because of the tiny size, unbound $\mathrm{Cu}$ ions can interact with bacterial membranes more effectively.

Copper oxide nanoparticles (CuONPs) are generated by combining copper salts (copper sulfate, copper acetate, and copper chloride) with reductants $(\mathrm{NaOH}$ and ascorbic acid) to form CuONPs [143]. With the decrease in size, the $\mathrm{CuONP}$ properties increase, and finely dispersed bioactive $\mathrm{CuONPs}$ are predicted to have a significant disinfectant action. Because of the tiny size, unbound $\mathrm{Cu}$ ions can interact with bacterial membranes more effectively [144]. Numerous techniques have been explained by the association of $\mathrm{CuO}$ nanoparticles, antibiotics, and natural active compounds into BCNF-based films to improve their antibacterial and antioxidant activities $[145,146]$. Copper oxide nanocomposite films are interesting for active packaging and reveal a higher antimicrobial effect against Gram-negative (E.coli) and Gram-positive (S. aureus) food spoiling microorganisms $[145,147,148]$ and also antioxidant activities such as DPPH and ABTS in AFP [149]. As a result, various studies on the effects of CuONPs on biopolymer films have been carried out.

\subsection{Physical and Mechanical Characteristics of Carbohydrate} Polymers Based on CuONPs. The mechanical features of materials principally depend on their performance in critical situations such as temperature, cooling rate, heating, deformation, applied force, and deformation rate [150]. Biopolymer composites' mechanical properties depend entirely on the biopolymer and its chemical construction, morphology, molecular weight, molecular orientation, crystallinity, copolymerization, plasticization, crosslinking filler type, and concentration, which determine expected functionalities as well as the importance of the material [150]. In general, the mechanical properties of composite films created by the blending process are determined by the interactions between the compounds and their miscibility and intermolecular cooperation between polymer chains [151]. There are a different variety of mechanical properties that improve in understanding the material and its characteristics, including tensile strength (TS), elongation at break (EB), elastic modulus (EM), Young's modulus (YM), thickness, yield stress, Poisson's ratio, storage, creep, and recoverable compliance [152].

Mechanical properties such as knock and tensile strengths considerably improve composites when bio-derived reinforcement materials are acclimatized into the biopolymers $[153,154]$. The polymer part in biocomposites helps the composite exhibit better mechanical properties in molecular weight, chemical components, morphology, and processing method, which helps impart desired functionalities to the material [155]. Meanwhile, imbued with bioderived nanoparticles and nanofibers, the ensuing biopolymers show development in moduli features, gas permeability, heat deformation temperature, decomposition, and, in individual, the tensile performance of the resulting component [156, 157]. For improved eco-friendly and economical, biopolymer nanocomposites encourage researchers to produce novel products compatible with various food packaging applications [158]. A particular portion of research devotion has been set on combining biopolymers with $\mathrm{CuO}$ nanoparticles that contain compounds such as cellulose, carboxymethylcellulose (CMC), and bacterial cellulose (BC), starch, agar, xanthan gum, gellan gum, and chitosan[158].

Shankar and his colleagues [142], combined copper nanoparticles with five types of biopolymers (agar, alginate, carrageenan, chitosan, and CMC). They investigated its mechanical properties, including thickness, TS, EB, EA, and TGA thermal stability (Table 2 ).

The alginate-CuONPs and CMC-CuONPs have the lowest and highest thickness compared to other films. The thickness of the biopolymer films was raised after the addition of CuONPs. The large number of CuONPs in the composite films caused the thickness of the films to expand. Biopolymer films" tensile strength (TS) varied based on the polymer type. Compared to other films, the lowest and maximum TS owing to agar-CuONPs and carrageenan- 
TABle 2: Physical properties of copper oxide biocomposite films as food packaging applications in different studies.

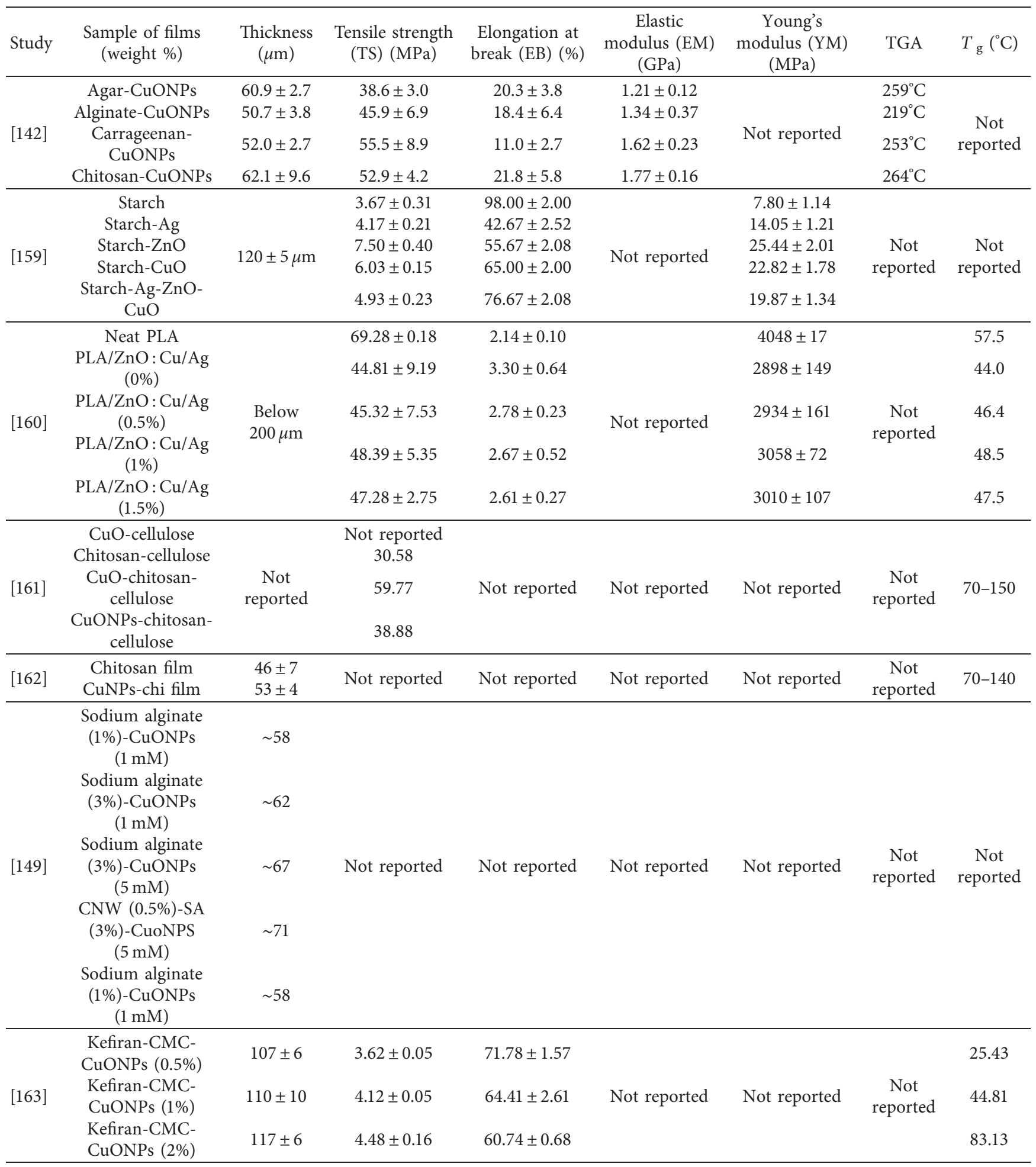

CuONPs were 38.6 MPa and 55.5 MPa, respectively. The TS and EM significantly improved in the chitosan, alginate, and CMC-based films. However, in the case of agar and carrageenan-based films, the TS rose little. The elastic modulus (EM) of CMC-CuONPs was the lowest with $1.08 \mathrm{GPa}$, and chitosan, carrageenan, alginate, and agar nanocomposite films were the highest at $1.77,1.62,1.34$, and $1.21 \mathrm{GPa}$, respectively. The nanocomposite films presented a more favorable TS and EM value than neat polymer films. On the opposite, the flexibility (EB) of the biopolymer films declined after incorporating CuONPs. The highest percentage of elongation at break (EB) refers to CMC, chitosan, agar, alginate, and carrageenan-CuONPs, with 54.2\%, 21.8\%, $20.3 \%, 18.4 \%$, and $11 \%$, respectively (Table 2 ). 
Thermal stability was measured using the thermogravimetric analysis (TGA) method. For all of the films, the first thermal degradation started at $80^{\circ} \mathrm{C}$. The evaporation of moisture caused this phase of thermal deterioration. The second stage differed depending on the kind of biopolymer film; this process is linked to the degradation of glycerol and biopolymers. For the CMC films, chitosan, agar, carrageenan, and alginate films, the highest temperatures for the second stage degradation were $277,270,248,229$, and $218^{\circ} \mathrm{C}$, respectively. When $\mathrm{CuO}$ nanoparticles were mixed, the highest degradation temperatures were altered to $277^{\circ} \mathrm{C}$, $264^{\circ} \mathrm{C}, 259^{\circ} \mathrm{C}, 253^{\circ} \mathrm{C}$, and $219^{\circ} \mathrm{C}$, respectively. After adding $\mathrm{CuONPs}$, the start temperatures for thermal disruption of carrageenan and agar films increased, decreasing in chitosan-based nanocomposite films. This might be owing to the copper ionic forms' configuration. However, there was no difference in the case of alginate- and CMC-based films. The film's mechanical properties are primarily determined by the polymer chains' thickness, density, concentration, and intermolecular and intramolecular interactions [164].

In a different study, Peighambardoust and his colleagues [159] investigated the role of starch biopolymer with silver, zinc, copper nanoparticles, and a combination.

This study assessed the physical and mechanical properties of starch-based nanocomposite films combining Ag, $\mathrm{CuO}$, and $\mathrm{ZnO}$ as single NPs or a mixture of NPs (Table 2).

The mechanical properties of nanocomposite films are influenced by two significant factors: to acquire the nanocomposite films' excellent mechanical properties, sufficient contact between the surface of nanoparticles and the biopolymer matrix is necessary. Moreover, the biopolymer matrix must have a homogenous dispersion of all nanoparticles [165]. Film samples such as starch-Ag, starch-ZnO, starch-CuO, and starch-Ag-ZnO-CuO of NPs were chosen for mechanical analysis, that is, thickness, TS, EB, and YM. A micrometer was used to measure the thickness of each film, which was $120 \pm 5 \mu \mathrm{m}$. $\mathrm{ZnO}, \mathrm{CuO}$, and $\mathrm{Ag}$ starch films were found to have tensile strengths of $7.50,6.03$, and $4.17 \mathrm{MPa}$, respectively. The tensile strength of the biopolymer containing starch, $\mathrm{Ag}, \mathrm{CuO}$, and $\mathrm{ZnO}$ film, on the other hand, was lower than CuONPs and higher than Ag NPs. At 2wt.\% of each nanoparticle, the TS of starch- $\mathrm{ZnO}$ film outperformed starch-Ag and starch-CuO films. The strong molecular interaction between starch chains and $\mathrm{ZnO}-\mathrm{NPs}$ appears to be the source of this issue [122] (Table 2).

They also confirmed that the EB status of the starch-Ag$\mathrm{ZnO}-\mathrm{CuO}$ nanocomposite film was higher than other film samples. The starch film had the highest EB, with $98 \%$, followed by starch-Ag- $\mathrm{ZnO}-\mathrm{CuO}$, starch-CuO, starch- $\mathrm{ZnO}$, and starch-Ag nanocomposite films with $76.67 \%, 65 \%$, $55.67 \%$, and $42.67 \%$, respectively (Table 2 ). The force required to extend the film was increased by biopolymer chains, resulting in a lower EB value. The mechanical strength of the resultant films is influenced by the interfacial interactions between nanofillers and their dispersion in the biopolymer matrix.

Young's modulus (YM) is another factor for evaluating mechanical strength. Peighambardoust et al. showed that starch-ZnO has the highest YM with $25.44 \mathrm{MPa}$, starch-
$\mathrm{CuO}$, starch-Ag-ZnO-CuO, starch-Ag with 22.82, 19.87, and 14.05 $\mathrm{MPa}$, respectively. These results showed that the starch-CuO film has a more potent ability, great flexibility, high YM, and TS than starch-ZnO and starch-Ag and can be a good film for AFP.

In another study, Vasile and his colleagues [160] demonstrated ZnO's effect: $\mathrm{Cu} / \mathrm{Ag}$ nanoparticles on the properties of plasticized PLA were examined in terms of architecture. Melt blending processing techniques provided polylactic acid (PLA) samples with embedded $\mathrm{Cu}$-doped $\mathrm{ZnO}$ powder functionalized with $\mathrm{Ag}$ nanoparticle composites (PLA/ZnO: $\mathrm{Cu} / \mathrm{Ag}$ ). They examined thermal stability and mechanical properties such as thickness, TS, EB, and YM with neat PLA and four different PLA nanocomposite films (0\%-1.5 wt.\%).

The thickness of neat PLA and each biopolymer nanocomposite film PLA/ZnO : Cu/Ag (0\%-0.5\%-1\% and 1.5\%) reported lower than 200 micrometers (Table 2). Compared to other nanocomposite films, the neat PLA had the highest tensile strength, with 69.28 MPa. Among the PLA/ZnO: $\mathrm{Cu} /$ Ag films, the 1 wt.\% had the maximum TS with $48.39 \mathrm{MPa}$, $1.5,0.5$, and 0 wt. $\%$ with $47.28,45.32$, and $44.81 \mathrm{MPa}$, respectively. The addition of $\mathrm{ZnO}: \mathrm{Cu} / \mathrm{Ag}$ nanoparticles into plasticized PLA has slowly increased the effect of the TS at the break with the highest value of 48-47 MPa for $\mathrm{ZnO}$ : $\mathrm{Cu} /$ Ag 1 or $1.5 \%$ (Table 2). This is likely due to a homogenous dispersion of $\mathrm{ZnO}$ : $\mathrm{Cu} / \mathrm{Ag}$ NPs into the PLA matrix and nanoparticles' high aspect ratio that reduces the chain movements. A similar advancement in PLA film mechanical properties of the nanocomposites strengthened with $\mathrm{Ag}-\mathrm{Cu}$ composite or $\mathrm{ZnO}$ nanoparticles [166, 167].

The elongation at break (EB) is another essential mechanical characteristic in food packaging. The lowest flexibility refers to a neat PLA with $2.14 \%$. On the other hand, PLA nanocomposite films had a higher EB than neat PLA. The PLA/ZnO : $\mathrm{Cu} / \mathrm{Ag} 0$ wt.\% has the highest EB with $3.30 \%$, followed by $0.5,1$, and 1.5 wt. $\%$ with $2.78 \%, 2.67 \%$, and $2.61 \%$, respectively (Table 2 ). These results presented that the EB decreased with the increase in the NP content. However, compared to the neat PLA, nanoparticles help in increasing the flexibility of films.

On the opposite of EB, neat PLA has the maximum YM value compared to PLA/ZnO: $\mathrm{Cu} / \mathrm{Ag}$ films, and the YM increased with the increase in the nanoparticle content. Vasile et al. explained that neat PLA has the highest YM with $4048 \mathrm{MPa}$. Among the PLA/ZnO: $\mathrm{Cu} / \mathrm{Ag}$ films, PLA/ZnO: $\mathrm{Cu} / \mathrm{Ag} 1 \%$ films have the highest YM with $3058 \mathrm{MPa}$, followed by $1.5,0.5$, and 0 wt. $\%$ with 3010,2934 , and $2898 \mathrm{MPa}$, respectively.

It is recognized that PLA below the functional processing conditions displays a low crystallinity. Due to the intrinsic slow crystallization rate, it is an amorphous shape, restricting its applications in the automotive and packaging fields. The cooperative influence of plasticizers and nucleating factors in the crystallinity enhancement was determined by investigating the thermal and mechanical characteristics of the PLA nanocomposites [168].

This study measured thermal stability by the differential scanning calorimetry (DSC) technique. The DSC curves of 
PLA nanocomposite films displayed a glass transition temperature (is described as the temperature at which 30-50 carbon chains began to move) [169], an excellent visible exothermal cold crystallization process, and the endothermal melting process as a double peak, apparently due to diverse sorts of crystallites with varying lamellar thickness or reorganization during melting. The glass-liquid transition, also known as the glass transition, is the gradual and reversible transition in amorphous materials from a hard and moderately brittle "glassy" state to a viscous or rubbery state when the temperature is increased [170]. The DSC curve of neat PLA is recognized as a transition at $57.5^{\circ} \mathrm{C}$ associated with the glass transition ( $\mathrm{Tg}$ ) relaxational process. Among the PLA nanocomposite films, PLA/ZnO: $\mathrm{Cu} / \mathrm{Ag} 1 \%$ has the highest $\mathrm{Tg}$ with $48.5^{\circ} \mathrm{C}$ compared to other films, which have $47.5,46.4$, and $44^{\circ} \mathrm{C}$ related to $1.5,0.5$, and 0 wt. $\%$, respectively (Table 2).

Mary et al. [161] investigated the tensile strength of chitosan-attached cellulose (CAC), copper-bound chitosanattached cellulose (CBCAC), and CuONP chitosan cellulose (NCLCAC) biopolymers. The results of TS analysis have been well described. The TS of CAC, CBCAC, and NCLCAC biopolymers was determined to be around 30.58, 59.77, and 38.88 $\mathrm{MPa}$, respectively (Table 2 ).

The presence of $\mathrm{Cu}$ (II) ions that bond firmly with the nitrogen atoms of the amino group of chitosan chains in the CBCAC biopolymer explains why the CBCAC biopolymer has more TS than the conventional CAC biopolymer. Plain and CuONPs-chitosan-cellulose (NCLCAC) biopolymers were shown in DSC thermograms. The glass transition temperature ( $\mathrm{Tg}$ ) for these samples is almost $70^{\circ} \mathrm{C}$ and $150^{\circ} \mathrm{C}$, respectively, indicating the thermal stability of biopolymers verified thanks to the CuONP coating (Table 2).

In one study, [162], the films' thickness and DSC were measured. The thickness of the chitosan and CuNP-chitosan films was $46 \mu \mathrm{m}$ and $53 \mu \mathrm{m}$, respectively. The nanocomposite film, which contained $0.17 \%$ colloidal CuNPs, increased the thickness of the chitosan film by $15 \%$. The DSC curves of films showed a primary endotherm change to lower temperature regarding CS powder for chitosan and CuNPschitosan films that happened above a temperature range $\left(70-140^{\circ} \mathrm{C}\right)$. This endotherm refers to water loss and describes the energy required to evaporate the water in the films. The moisture retentivity of chitosan film was affected when colloidal CuNPs were added. The composite film's expected energy is much lower, maybe, because of the loss of the hydrogen bonding caused by the sterical barrier of colloidal CuNPs. Compared to the chitosan film, the composite film had a weaker exotherm at $228^{\circ} \mathrm{C}$.

The hopeful mechanical characteristics of polymer composite films make it possible to use them in food packaging and technology. Saravanakumar et al. [149] produced four combination films with cellulose, sodium alginate (SA), and $\mathrm{CuO}$ nanoparticles with various food packaging concentrations for food packaging, and showed the thickness as mechanical characteristics but not reported the TS, EB, EM, YM, and thermal stability. In this study, the thickness of sodium alginate (1\%)-CuONPs ( $1 \mathrm{mM})$, sodium alginate (3\%)-CuONPs $(1 \mathrm{mM})$, sodium alginate (3\%)-
CuONPs $(5 \mathrm{mM})$, and cellulose nanowhisker (CNW) (0.5\%)-SA (3\%)-CuoNPS $(5 \mathrm{mM})$ were determined to be around $\sim 58, \sim 62, \sim 67$, and $\sim 71 \mu \mathrm{m}$, respectively. This issue explained that the thickness of the polymeric films rose with the CuONPs, and the SA concentration increased. Similar effects were recognized with cellulose nanocomposite films embedded with ZnO-NPs [138, 171] (Table 2).

In a study, Oun et al. [172] investigated carrageenan films prepared by combining with $\mathrm{ZnO}, \mathrm{CuONPs}$, and their combination. The mechanical characterization was evaluated based on thickness, TS, EB, and EM for carrageenan$\mathrm{KCl}$, carrageenan-KCl-ZnO (1\%), carrageenan-KCl-ZnO $(0.5 \%)-\mathrm{CuO}(0.5 \%)$, and carrageenan-KCl-CuO (1\%) (Table 2). According to the thickness, it was concluded that the nanocomposite film containing zinc oxide was less thick than copper oxide nanoparticles. However, the carrageenan$\mathrm{KCl}-\mathrm{ZnO}(0.5 \%)-\mathrm{CuO}(0.5 \%)$ composite had a thickness between these two nanocomposite films.

The neat carrageenan had the highest TS and EM, with 55.2 $\mathrm{MPa}$ and 3.37 GPa compared to other films. The TS for carrageenan-KCl-ZnO (0.5\%), carrageenan-KCl, carrageenan-KCl-ZnO (0.5\%)- $\mathrm{CuO}(0.5 \%)$, and carrageenan/ $\mathrm{KCl}-\mathrm{CuO}(1 \%)$ was $48.2,44.9,32.9$, and $30.4 \mathrm{MPa}$, respectively. The EM was measured for carrageenan-KCl- $\mathrm{ZnO}$ $(0.5 \%)$, carrageenan- $\mathrm{KCl}$, carrageenan-KCl-ZnO (0.5\%)$\mathrm{CuO}(0.5 \%)$, and carrageenan-KCl-CuO (1\%) with 2.37, $2.24,0.89$, and $0.88 \mathrm{GPa}$, respectively.

After the fillers were added, the TS and EM of the neat carrageenan film decreased dramatically. The recrystallized $\mathrm{KCl}$ in the polymer matrix caused fissures in the polymer matrix, resulting in a decrease in the film's TS and EM. The EB films altered depending on nanofiller types, although their performance was contrary to the TS and EM. The carrageenan-KCl- $\mathrm{ZnO}(0.5 \%)-\mathrm{CuO}(0.5 \%)$ and neat carrageenan had the highest and lowest EB compared to other films with $18.2 \%$ and $6.6 \%$, respectively. After that, carrageenan-KCl-CuO (1\%), carrageenan-KCl-ZnO (1\%), and carrageenan- $\mathrm{KCl}$ with $15.9 \%, 10.3 \%$, and $6.7 \%$ respectively (Table 2).

Using thermogravimetric analysis, the thermal stability of carrageenan-based films was investigated (TGA). Carrageenan- $\mathrm{KCl}$, carrageenan- $\mathrm{KCl}-\mathrm{ZnO}$ (0.5\%)-CuO, and carrageenan-KCl- $\mathrm{ZnO}(0.5 \%)-\mathrm{CuO}$ were all decomposed at $210^{\circ} \mathrm{C}$. However, the carrageenan-KCl-CuO (1\%) film lowered to $200^{\circ} \mathrm{C}$. In contrast, it expanded to $228^{\circ} \mathrm{C}$ in the carrageenan-KCl-ZnO (1\%) film. The maximum breakdown temperatures $\left(T_{\max }\right)$ of the films were $228^{\circ} \mathrm{C}, 222.5^{\circ} \mathrm{C}$, $222.5^{\circ} \mathrm{C}, 252^{\circ} \mathrm{C}$, and $228^{\circ} \mathrm{C}$ for carrageenan, carrageenan$\mathrm{KCl}$, carrageenan-KCl-CuO (1\%), carrageenan-KCl-ZnO $(1 \%)$, and carrageenan- $\mathrm{KCl}-\mathrm{ZnO}(0.5 \%)-\mathrm{CuO}(0.5 \%)$, respectively, as determined by the peak temperature in the DTG curve (Table 2).

In another study conducted by Hasheminya and his colleagues [163], they investigated the kefiran-CMC biopolymer's mechanical properties by increasing copper oxide nanoparticle concentration. This study combined three concentrations of $1 \%, 1.5 \%$, and $2 \%$ copper oxide nanoparticles with the kefiran-CMC biopolymer. According to the findings, the thickness of the biopolymers rose as the 
concentration of copper oxide nanoparticles increased. The highest thickness was due to kefiran-CMC-CuONPs (2\%) with $117 \mu \mathrm{m}$ followed by CuONPs (1.5\%) and CuONPs (0.5\%) with 110 and $107 \mu \mathrm{m}$, respectively (Table 2). With increasing copper oxide nanoparticle concentration, the contact angle of the films rose as well. From maximum to minimum, the contact angle was due to kefiran-CMCCuONPs (2\%), kefiran-CMC-CuONPs (1.5\%), and kefiranCMC-CuONPs (0.5\%) with $43.79^{\circ}, 40.12^{\circ}$, and $37.38^{\circ}$, respectively.

Increasing the angle of films in hydrophobic environments is associated with decreased hydrophobic compounds and decreases in hydroxyl groups in the biopolymers [173]. One of the reasons could be the hydrophobicity of copper oxide nanoparticles [174].

Like the contact angle and thickness, the tensile strength of the copper oxide nanoparticles increased. The highest TS was due to kefiran-CMC-CuONPs (2\%) with $4.48 \mathrm{MPa}$, followed by kefiran-CMC-CuONPs (1.5\%) and kefiranCMC-CuONPs (0.5\%) with 4.12 and $3.62 \mathrm{MPa}$, respectively (Table 2). This is due to hydrogen bonding between the hydroxyl groups of the copper oxide nanoparticles and the kefiran-CMC biopolymer. It is in line with the study by Rao et al. [175], which investigated the role of copper oxide nanoparticles in polyvinyl alcohol composite films. The composite film's increased tensile strength was credited with bonding in the hydroxyl groups of polyvinyl alcohol and copper oxide nanoparticles. Contrary to the tensile strength, contact angle, and thickness, the elongation at break decreased with the increasing concentration of nanoparticles. The lowest EB was due to kefiran-CMC-CuONPs (2\%) with $60.74 \%$ followed by kefiran-CMC-CuONPs (1\%) and kefiran-CMC-CuONPs (0.5\%) with $64.41 \%$ and $71.78 \%$, respectively. Shankar et al. [142] reported the same result investigated on alginate, chitosan, and carrageenan, which we described earlier. Thermal analysis in this study showed that both heat transfer steps increased with the increasing concentration of copper oxide nanoparticles in the biopolymer. The film's glass temperature $(\mathrm{Tg})$ reached 25.43, 44.81 , and $83.13^{\circ} \mathrm{C}$ for $0.5 \%, 1 \%$, and $2 \%$ concentrations, respectively, in the upper heat transfer phase. The lower thermal transition stage of the control film was $-44.55^{\circ} \mathrm{C}$ and was reported in films with $0.5 \%, 1 \%$, and $2 \% \mathrm{CuONP}$ concentrations at $-6.16,10.72$, and $37.8^{\circ} \mathrm{C}$, respectively (Table 2).

The above studies show that copper nanoparticles can combine with various biopolymers, including starch, chitosan, agar, carrageenan, alginate, polylactic acid, cellulose (CMC, CNW, BC), and other polymers. With that, thickness, tensile strength (TS), and film flexibility are increased.

3.4. Food Barriers of CuO-Carbohydrate Films. Managing water vapor and gas emission rates is essential to reach adequate quality, safety, and shelf life for moisture-sensitive foods. Beyond packaging, high-performance films with high elasticity, optical clarity, mechanical strength, thermal stability, biodegradability, and gas barrier properties are needed for various applications [176]. Carbohydrates, especially polysaccharides, have high-quality material for excellent mechanical features, but it has a weak water vapor transfer barrier. On the other hand, combining lipids provides acceptable water vapor barrier qualities; however, the resulting films are frequently opaque, brittle, and unsteady and have a waxy taste [177]. Nanocomposites are combined in the materials' biopolymer matrix due to their large surface area, favoring the filler-matrix cooperation and activity.

Furthermore, the nanocomposites reinforce the act as little barriers for gases by complicating the material [14]. Plastics are approximately penetrable to small molecules such as vapors (gases such as $\mathrm{O}_{2}, \mathrm{CO}_{2}, \mathrm{~N}_{2}$, and $\mathrm{H}$, water, and organic vapors) or liquids. Water vapors and gases are two principal penetrable considered in packaging purposes. These composites may transfer from the inner or outer environment through the polymer package wall, following a constant change in product property, reducing the shelf life $[178,179]$. Most fresh foods are spoiled due to high humidity [180].

3.4.1. Water Vapor Permeability (WVP). Water vapor permeability (WVP) can estimate water vapor barrier features, which uses the differential pressure and thickness of the packaging material and shows the quantity of water infiltrated per unit area and time $(\mathrm{kg} / \mathrm{m} s \mathrm{~Pa})$. Fresh food items, such as vegetables, require water vapor barrier properties to avoid dehydration. In contrast, other foods, such as bread or dry foods, require water vapor barrier features to prevent moisture absorption from the environment, which is critical [179]. Another water vapor permeability factor is the water vapor transmission rate (WVTR) used in bread packaging, as expressed in $\mathrm{cc} \cdot \mathrm{m}^{-2} \cdot \mathrm{s}^{-1}$ (or $\mathrm{gm}^{-2} \cdot$ day $^{-1}$ ) [55].

3.4.2. Oxygen and Carbon Dioxide Permeability. Limiting gas transfer into food packaging for longer shelf life is a significant challenge for packagers. The transfer of oxygen into a beer bottle can cause it to be stale; similarly, its presence in the soda bottle can reduce its shelf life [181]. The effect of oxygen on food and container shelf life is complex. Oxygen is essential for certain foods to prevent the matrix from rapidly deteriorating. For instance, there is respiratory metabolism in fresh fruits and vegetables. However, it is not difficult to say that oxygen is considered the main enemy of many food products $[49,182]$. This is a significant cause of chemical degradation for several matrices because it is associated with harmful reactions.

Due to the quick oxidation of lipids and vitamins in the food or by improving microorganisms such as aerobic bacteria, yeasts, and molds, the presence of oxygen in food packaging causes rapid food loss $[49,182]$. The presence of oxygen in packaging causes additional adverse effects on enzymatic systems. Using oxygen as a second substrate for enzymatic function may cause water and beverage discoloration. Lipases are lipolytic enzymes that hydrolytically stimulate the release of free fatty acids from triglyceride molecules. The presence of oxygen may catalyze the plant's browning tissues by polyphenol oxidase, [183]. Due to 
oxygen, all of the above destructive reactions can lead to discoloration or taste of the food, leading to food poisoning, slowing food life, and endangering consumers' health and safety.

As a result, one of the essential aims in the food packaging sector is to manage the oxygen inside the package and its exposure to the food [182]. The presence of carbon dioxide gas at the right concentration can inhibit or slow down bacteria's growth, thereby helping the freshness in the food packaging [184]. The antimicrobial role can also act as an antioxidant and prevent food from maintaining oxidation [185]. On the other hand, depending on the type of food (such as yoghurt) and its storage temperature, it can accumulate a lot of carbon dioxide, which results in lost quality of the food product and its packaging [55]. To this end, making a biopolymer nanocomposite with suitable barrier properties for packaging, preserving food quality, and reducing plastic consumption is one of the urgent needs today. In recent years, research on the joint role of copper oxide nanoparticles and biopolymers has been undertaken, which we shall examine in this section.

Shankar and his colleagues [142] combined copper nanoparticles with five different biopolymers (agar, alginate, carrageenan, chitosan, and CMC). They investigated its barriers to properties, such as WVP, and used UV light for optical transparency. The films were exposed for $48 \mathrm{~h}$ at $25^{\circ} \mathrm{C}$ and $50 \% \mathrm{RH}$ before determination. Among the films, the carrageenan film showed the highest WVP value $\left(1.84 \pm 0.26 \times 10^{-9} \mathrm{~g} \mathrm{~m} / \mathrm{m}^{2}\right.$.Pa.s $)$ followed by alginate, CMC, agar, and chitosan films with $1.74 \pm 0.08,1.72 \pm 0.34$, $1.54 \pm 0.18$, and $1.09 \pm 0.23 \times 10^{-9} \mathrm{~g} \mathrm{~m} / \mathrm{m}^{2}$.Pa.s, respectively (Table 3 ). The WVP of the biopolymer-based films reduced significantly following the incorporation of $\mathrm{CuO}$ nanoparticles. In this regard, the highest WVP value for nanocomposite films refers to CMC-CuONPs with $1.40 \pm 0.08 \times 10^{-9} \mathrm{~g} \mathrm{~m} / \mathrm{m}^{2}$.Pa.s. followed by alginateCuONPs, carrageenan-CuONPs, agar-CuONPs, and chitosan-CuONPs nanocomposite films with $1.35 \pm 0.17$, $1.19 \pm 0.08,1.18 \pm 0.06$, and $1.03 \pm 0.17 \times 10^{-9} \mathrm{~g} \mathrm{~m} / \mathrm{m}^{2}$.Pa.s, respectively. Water vapor impermeable metallic nanoparticles (MNPs) formed an indirect conduit for water vapor diffusion through the polymer matrix, resulting in a decrease in WVP [186] (Table 3).

The percentage of light transmission in UV and visible areas was calculated by applying a spectrophotometer, and the results were presented. Compared to nanocomposite films, the neat carbohydrate-based polymer films were extremely transparent. In this regard, at visible light $\left(T_{660}\right)$, the carrageenan film showed the highest light transmission with $89.6 \pm 0.6 \%$. After that, agar and chitosan had the same light transmission with $89.1 \pm 0.5$ and $89.1 \pm 0.3 \%$, respectively, followed by alginate with $88.7 \pm 0.3$ and $87.7 \pm 0.9 \%$, respectively. At the same visible light $\left(\mathrm{T}_{660}\right)$, the percentage of light transmission in the nanocomposite films decreased. The chitosan-CuONPs was the highest transmittance light with $75.4 \pm 0.9 \%$ followed by carrageenan-CuONPs, alginate-CuONPs, agar-CuONPs, and CMC-CuONPs with $15.8 \pm 0.9 \%, 14.3 \pm 0.4 \%, 13.9 \pm 0.7 \%$, and $9.63 \pm 0.5 \%$, respectively (Table 3 ).
At the wavelength of UV light $\left(\mathrm{T}_{280}\right)$, similar results were obtained with visible light results, meaning that at ultraviolet wavelengths, the transmission of light in nanoparticle-free biopolymers was higher than that of those with copper nanoparticles. The carrageenan film was the highest light transmission at wavelengths of UV light, with $73.9 \pm 1.1 \%$. followed by alginate, CMC, agar, and chitosan with $67.0 \pm 1.0 \%, 58.3 \pm 2.5 \%, 49.1 \pm 1.2 \%$, and $8.8 \pm 6.0 \%$, respectively (Table 3). At the same wavelength, the light transmission in nanocomposite films is reduced. In this term, carrageenan-CuONPs with $9.3 \pm 1.1$ had the maximum transmission, followed by alginate, agar, CMC, and chitosan nanocomposites with $6.2 \pm 0.4,3.75 \pm 0.3,1.4 \pm 0.1$, and $0.1 \pm 0.0$, respectively. Compared to other biopolymer films, the transparency of chitosan-based films decreased only a little. This could be due to the acetic acid in the chitosanbased composite film converting CuONPs to copper ions. Their result indicated that the MNP performed an essential role against both UV and visible lights of all the films and decreased significantly after incorporating $\mathrm{CuO}$ nanoparticles [142]. This chiefly depended on UV light absorption by nanoparticles dispersed in the film matrix [187]. Like this report, Shankar et al. also observed the lower transmission of UV light in the Agar-CuO nanoparticles [143]. The combination of copper nanoparticles with various biopolymers reduces the transparency of films due to the surface plasmon resonance (SPR) of $\mathrm{CuO}$ nanoparticles [188].

Therefore, WVP should be as low as possible to determine the lowest moisture content in the food packaging and the surrounding atmosphere to keep the quality $[189,190]$. In this regard, a study recognized the role of starch biopolymer with silver, zinc, copper nanoparticles, and a combination to assess the WVP and water solubility films. Peighambardoust et al. [159] showed WVP of the neat starch film and nanocomposite films combining single and a combination of $\mathrm{CuO}, \mathrm{ZnO}$, and $\mathrm{Ag}$ nanoparticles at varied concentrations. Before calculation, the films were exposed for $48 \mathrm{~h}$ at $25^{\circ} \mathrm{C}$ and $50 \pm 5 \% \mathrm{RH}$. Regardless of the nanoparticles used in starch, this study clearly showed that by adding nanoparticles, the starch film nanocomposites' water vapor content decreased compared to that of a pure starch film. This property increased with increasing concentrations of copper oxide, zinc oxide, and silver nanoparticles. By increasing the \%weight of copper oxide nanoparticles in the starch matrix, water vapor permeation becomes more severe, reducing WVP. The same is valid for the zinc and silver nanoparticles [172].

On the other hand, filling the spaces in the starch biopolymer matrix and forming hydrogen bonds in the starch macromolecular chains reduce water penetration and, ultimately, water vapor permeability in the film [190]. However, WVP was lower in the St-Ag-ZnO-CuO film at equal concentrations than all other films, reportedly due to the uniformity and dispersion of copper oxide, zinc oxide, and silver nanoparticles.

Water solubility (WS) is another crucial barrier feature in biopolymers. In this study, nanocomposites containing a single or a combination of zinc oxide, silver, and copper oxide nanoparticles were investigated. Regardless of the 
TABLE 3: Food barriers of copper oxide biocomposite films as food packaging applications in different studies.

\begin{tabular}{|c|c|c|c|c|c|c|c|c|}
\hline Study & Film sample & $\begin{array}{l}\text { Vis light } \\
(600 \mathrm{~nm})\end{array}$ & WVP & WS (\%) & RH & $\begin{array}{c}\mathrm{CO}_{2} \\
\left(\mathrm{~mL} \cdot \mathrm{m}^{-2} \mathrm{day}^{-1}\right)\end{array}$ & $\begin{array}{c}\mathrm{O}_{2} \\
\left(\mathrm{~mL} \cdot \mathrm{m}^{-2} \text { day }^{-1}\right)\end{array}$ & $\begin{array}{l}\text { Moisture } \\
(\%)\end{array}$ \\
\hline \multirow{5}{*}[142]{} & Agar/CuONPs & $13.9 \pm 0.7$ & $1.18 \pm 0.06$ & \multirow{5}{*}{$\begin{array}{l}\text { Not } \\
\text { reported }\end{array}$} & \multirow{5}{*}{$\begin{array}{c}50 \% \mathrm{RH} \text { for } \\
48 \mathrm{~h}, 25^{\circ} \mathrm{C}\end{array}$} & \multirow{5}{*}{ Not reported } & \multirow{5}{*}{ Not reported } & \multirow{5}{*}{$\begin{array}{l}\text { Not } \\
\text { reported }\end{array}$} \\
\hline & Alginate/CuONPs & $14.3 \pm 0.4$ & $1.35 \pm 0.17$ & & & & & \\
\hline & $\begin{array}{l}\text { Carrageenan/ } \\
\text { CuONPs }\end{array}$ & $15.8 \pm 0.9$ & $1.19 \pm 0.08$ & & & & & \\
\hline & Chitosan/CuONPs & $75.4 \pm 0.9$ & $1.03 \pm 0.17$ & & & & & \\
\hline & $\mathrm{CMC} / \mathrm{CuONPs}$ & $9.63 \pm 0.5$ & $1.40 \pm 0.08$ & & & & & \\
\hline \multirow{5}{*}{ [159] } & Starch & \multirow{5}{*}{$\begin{array}{l}\text { Not } \\
\text { reported }\end{array}$} & $11.46 \pm 0.23$ & $32.25 \pm 0.85$ & \multirow{5}{*}{$\begin{array}{r}50 \pm 5 \% \mathrm{RH} \\
\text { for } 48 \mathrm{~h}, 25^{\circ} \mathrm{C}\end{array}$} & \multirow{5}{*}{ Not reported } & \multirow{5}{*}{ Not reported } & \multirow{5}{*}{$\begin{array}{l}\text { Not } \\
\text { reported }\end{array}$} \\
\hline & Starch-Ag (1\%) & & $10.49 \pm 0.14$ & $30.13 \pm 0.74$ & & & & \\
\hline & Starch-ZnO (1\%) & & $10.15 \pm 0.14$ & $27.57 \pm 0.81$ & & & & \\
\hline & \multirow{2}{*}{$\begin{array}{l}\text { Starch-CuO }(1 \%) \\
\text { Starch-Ag-ZnO- } \\
\mathrm{CuO}\end{array}$} & & $10.79 \pm 0.20$ & $30.86 \pm 0.60$ & & & & \\
\hline & & & $10.70 \pm 0.24$ & $30.61 \pm 0.47$ & & & & \\
\hline \multirow{5}{*}[160]{} & Neat PLA & \multirow{5}{*}{$\begin{array}{l}\text { Not } \\
\text { reported }\end{array}$} & 15.94 & \multirow{5}{*}{$\begin{array}{l}\text { Not } \\
\text { reported }\end{array}$} & \multirow{5}{*}{ Not reported } & 873 & 1308 & \multirow{5}{*}{$\begin{array}{l}\text { Not } \\
\text { reported }\end{array}$} \\
\hline & $\begin{array}{c}\mathrm{PLA} / \mathrm{ZnO}: \mathrm{Cu} / \mathrm{Ag} \\
(0 \%)\end{array}$ & & 13.70 & & & 260 & 104 & \\
\hline & $\begin{array}{c}\mathrm{PLA} / \mathrm{ZnO}: \mathrm{Cu} / \mathrm{Ag} \\
(0.5 \%)\end{array}$ & & 11.35 & & & 230 & 97 & \\
\hline & $\begin{array}{c}\mathrm{PLA} / \mathrm{ZnO}: \mathrm{Cu} / \mathrm{Ag} \\
(1 \%)\end{array}$ & & 18.72 & & & Invalid test & Invalid test & \\
\hline & $\begin{array}{c}\mathrm{PLA} / \mathrm{ZnO}: \mathrm{Cu} / \mathrm{Ag} \\
(1.5 \%)\end{array}$ & & 15.60 & & & Invalid test & Invalid test & \\
\hline$[162]$ & $\begin{array}{l}\text { Chitosan film } \\
\text { CuONPs-chi film }\end{array}$ & $\begin{array}{c}\text { Not } \\
\text { reported }\end{array}$ & $\begin{array}{l}3 \times 10^{-3} \pm 0.0001 \\
3 \times 10^{-4} \pm 0.0001\end{array}$ & $\begin{array}{c}\text { Not } \\
\text { reported }\end{array}$ & $\begin{array}{c}50 \% \mathrm{RH} \text { for } \\
24 \mathrm{~h}, 20^{\circ} \mathrm{C}\end{array}$ & Not reported & Not reported & $\begin{array}{c}33.7 \pm 1.7 \\
6.1 \pm 2.2 \\
\end{array}$ \\
\hline \multirow{4}{*}{ [149] } & $\begin{array}{c}\text { Sodium alginate } \\
(1 \%)-\mathrm{CuONPs} \\
(1 \mathrm{mM}) \\
\text { Sodium alginate }\end{array}$ & \multirow{4}{*}{$\begin{array}{l}\text { Not } \\
\text { reported }\end{array}$} & \multirow{4}{*}{ Not reported } & \multirow{4}{*}{$\begin{array}{l}\text { Not } \\
\text { reported }\end{array}$} & \multirow{4}{*}{ Not reported } & \multirow{4}{*}{ Not reported } & \multirow{4}{*}{ Not reported } & $\sim 12.6$ \\
\hline & $\begin{array}{c}\text { (3\%)-CuONPs } \\
(1 \mathrm{mM}) \\
\text { Sodium alginate }\end{array}$ & & & & & & & $\sim 12.4$ \\
\hline & $\begin{array}{c}(3 \%)-\mathrm{CuONPs} \\
(5 \mathrm{mM})\end{array}$ & & & & & & & $\sim 14.7$ \\
\hline & $\begin{array}{c}\text { CNW }(0.5 \%)-S A \\
(3 \%)-C u o N P S \\
(5 \mathrm{mM})\end{array}$ & & & & & & & $\sim 13$ \\
\hline
\end{tabular}

nanoparticles used in the starch matrix, the metal nanoparticles' composition in the starch matrix significantly reduced its solubility in water, increasing nanoparticle concentration. Compared to zinc and silver nanoparticles, copper oxide nanoparticles did not perform well in this respect. This might be for water solubility, as compounds containing copper oxide nanoparticles increase; on the other hand, they reduce hydrogen bonds [191].

Vasile et al. [160] demonstrated ZnO's effect: $\mathrm{Cu} / \mathrm{Ag}$ nanoparticles on plasticized PLA properties. The water vapor and gas permeability transmittance rate of the developed bionanocomposites is utterly described. The water vapor transmittance rate of neat PLA was $15.94 \mathrm{~g} \cdot \mathrm{m}^{-2}$ day $^{-1}$. Among the PLA/ZnO: $\mathrm{Cu} / \mathrm{Ag}$ films, the 1wt.\% had the highest water vapor transmittance rate, with $18.72 \mathrm{~g} \cdot \mathrm{m}^{-2}$ day $^{-1}$ compared to other nanocomposite films followed by $1.5,0$, and 0.5 wt. $\%$ with $15.6,13.70$, and $11.35 \mathrm{~g} \cdot \mathrm{m}^{-2} \mathrm{day}^{-1}$, respectively (Table 3 ).

The gas permeability transmittance rate was reported for neat PLA, 0, and 0.5 wt.\% of PLA/ZnO: $\mathrm{Cu} / \mathrm{Ag}$ films. The transmittance rate of carbon dioxide $\left(\mathrm{CO}_{2}\right)$ and oxygen $\left(\mathrm{O}_{2}\right)$ was determined at 873 and $1308 \mathrm{~mL} \cdot \mathrm{m}^{-2}$ day $^{-1}$ for neat PLA, respectively, followed by 260 and $104 \mathrm{~mL} \cdot \mathrm{m}^{-2}$ day $^{-1}$ for PLA/ZnO: $\mathrm{Cu} / \mathrm{Ag}(0 \%)$, and 230 and $107 \mathrm{~mL} \cdot \mathrm{m}^{-2}$ day $^{-1}$ for 0.5 wt. $\%$ of PLA/ZnO: Cu/Ag films, respectively (Table 3). At high concentrations of $\mathrm{ZnO}: \mathrm{Cu} / \mathrm{Ag}$ nanoparticles, their heterogeneous aggregation and dispersion can reduce and negatively affect these barrier properties. According to the results of this investigation, $0.5 \% \mathrm{ZnO}$ : $\mathrm{Cu} / \mathrm{Ag}$ NPs have the best barrier characteristics and are appropriate for packing.

In a study by Cardenas et al. [162], water vapor permeability (WVP), and moisture content on pure chitosan biopolymer and chitosan-CuONPs nanocomposite film were investigated. The films were exposed for two $h$ at $20^{\circ} \mathrm{C}$ and 50\% RH before the WVP examination (Table 3 ).

WVP is an essential factor in detecting water vapor permeability and removal from the matrix. Chitosan films showed higher WVP than films containing copper oxide nanoparticles. The WVP for chitosan and chitosan-CuONP films determined $3 \times 10^{-3}$ and $3 \times 10^{-4}\left(\mathrm{~g} \mathrm{~mm} / \mathrm{m}^{2}\right.$ day $\left.\mathrm{kPa}\right)$. Copper oxide nanoparticles increased water resistance and decreased WVP resistance. This may be due to the 
interaction of hydrogen bonds between chitosan and solvent area or roughness affecting the permeability. Equilibrium moisture content (EMC) for chitosan-copper oxide film was lower than that for the chitosan film due to the colloidal solution used in its preparation. The addition of metal nanoparticles due to ionic or bipolar-dipole bonding to the matrix biopolymer reduces the water's impact on the film. The EMC of the chitosan film was determined $33.7 \%$, while that of the chitosan-CuO nanoparticles film was $6.1 \%$ (Table 3).

In the study by Saravanakumar et al. [149], they produced combination films with cellulose, sodium alginate (SA), and $\mathrm{CuO}$ nanoparticles with various concentrations. The moisture content was different between the films of $\mathrm{CuO}$ nanocomposite biopolymers. The highest amount was related to sodium alginate (3\%)-CuONPs $(5 \mathrm{mM})$ biopolymer with about $14.7 \%$ moisture content. Then, CNW (0.5\%)-SA (3\%)-CuoNPs ( $5 \mathrm{mM})$ was about $13 \%$. The moisture content of sodium alginate (1\%)-CuONPs $(1 \mathrm{mM})$ and sodium alginate (3\%)-CuONP (1 mM) nanocomposite biopolymers was about $12.5 \%$ (Table 3 ).

In another study conducted by Hasheminya and his colleagues [163], they investigated the kefiran-CMC biopolymer's mechanical properties by increasing the concentration of copper oxide nanoparticles from $0.5 \%, 1 \%$, and $2 \%$ (Table 3 ). As the concentration of copper oxide nanoparticles increased, water permeability decreased. So, the nanocomposite with a concentration of $0.5 \%$ had the lowest water permeability. The WVP for every biocomposite film was 2.30, 2.65, and $3.81\left(10^{-7} \mathrm{~g} \mathrm{~m} / \mathrm{m}^{2} \mathrm{~Pa} . \mathrm{h}\right)$ for kefiran-CMCCuONPs (2\%), kefiran-CMC-CuONPs (1\%), and kefiranCMC-CuONPs (0.5\%), respectively. Copper oxide nanoparticles have a low hydrophobicity and permeability compared to the polymer matrix. On the other hand, the gaps between the polymer chains were filled in, thus reducing the mobility of the chain and reducing WVP [139] (Table 3).

The WVP for every biocomposite films was 2.30, 2.65, and $3.81(10-7 \mathrm{~g} \mathrm{~m} / \mathrm{m} 2 \mathrm{~Pa} . \mathrm{h})$ for kefiran-CMC-CuONPs (2\%), kefiran-CMC-CuONPs (1\%), and kefiran-CMCCuONPs $(0.5 \%)$, respectively. Copper oxide nanoparticles have a low hydrophobicity and permeability compared to the polymer matrix. On the other hand, the gaps between the polymer chains were filled, which reduces the mobility of the chain and reduces WVP [140] (Table 3).

3.5. Antioxidant Activities in CuO-Carbohydrate Films. Active antioxidant substances are active packaging types, especially for supplements and additives, to maintain food quality in transportation and packaging. This is due to their penetration into the enzymatic systems of some pathogens [192]. This innovative packaging is designed to maintain food quality against oxidation [193]. Aerobic bacteria and insects need oxygen to grow so that oxygen absorbers can prevent them from growing [194]. Because oxygen can easily pass through different membranes, exposure to excess oxygen can lead to microorganisms' growth [195]. Changes in antioxidants' structure can affect their shielding effect, and the food may spoil after a short time [196,197]. Oxidation of fats, pigments, and oxygen-sensitive vitamins such as vitamins $\mathrm{A}$ and $\mathrm{C}$ can alter the texture, taste, odor, and quality of food [198].

Most importantly, such chemical changes cause toxic aldehydes due to the destruction of unsaturated fatty acids [199]. Polymeric antioxidants are a group of substances that exhibit potent antioxidant and medicinal properties compared to low-molecular-weight compounds. They are made from polymerizing antioxidant molecules or biopolymer compounds (naturally and artificially) [192]. Antioxidant polymers have both polymeric and antioxidant properties. Enzymatic or chemical methods can be used to synthesize antioxidants. The obtained materials can retain their antioxidant properties and have excellent resistance in the macromolecular systems [192]. Proper selection of antioxidant compounds in food packaging is essential. Combining antioxidants and lubricants to achieve a one-handed product should be considered.

On the other hand, the type of antioxidant should be suitable for the type of food; for example, the polar antioxidant is ideal for packing high-fat foods and vice versa. This condition is called the "antioxidant paradox" [199]. Edible coating technology is an active nanopackaging that can reduce food spoilage. The primary mechanism is reducing the oxygen transfer rate and the possibility of incorporating antioxidant substances into the coating matrix or edible film. One solution is to use nanoparticles in the matrix coating [199]. The role of copper oxide nanoparticles in edible films is discussed below. Revathi et al. [56] investigated copper nanoparticles' antioxidant role in an edible biopolymer using the DPPH and ABTS method. This study analyzed the antioxidant properties of copper oxide, chitosan, chitosan-CuO, NS-CuO, and chi-CuO-NS biocomposites at different concentrations $(5,25,50,75$, and $100 \mu \mathrm{g} / \mathrm{mL})$. The DPPH radical scavenging assay obtained the highest EC50 for chitosan with $92.55 \mu \mathrm{g} / \mathrm{mL}$, followed by $\mathrm{CuO}$, chi-CuO, NS-CuO, and chi-CuO-NS with 91.71, 90.03, 88.03, and $76.02 \mu \mathrm{g} / \mathrm{mL}$, respectively. Based on the EC50, chi- $\mathrm{CuO}$ and $\mathrm{NS}-\mathrm{CuO}$ have significant radical scavenging activity compared to $\mathrm{CuO}$ and are similar to its result. This may be due to the phytochemicals in neem and chitosan attached to the copper oxide [200] (Table 4). The CS-CuONS biocomposite at $100 \mu \mathrm{g} / \mathrm{mL}$ concentration showed about $59 \%$ and $56 \%$ radical scavenging activity for DPPH and ABTS. While positive control, ascorbic acid was inhibited at the same concentration of about $70 \%$ and $72 \%$, respectively. The ABTS radical scavenging assay for chitosan obtained the highest EC50 value with $92.06 \mu \mathrm{g} / \mathrm{mL}$, among other composites followed by $\mathrm{CuO}, \mathrm{CS}-\mathrm{CuO}$, NS-CuO, and CS-CuONS with $91.05,90.95,89.99$, and $88.53 \mu \mathrm{g} / \mathrm{mL}$, respectively (Table 4).

Besides, the percentage of inhibition in chitosan- $\mathrm{CuO}$ biocomposite is similar to copper oxide particles because chitosan has less antioxidant activity due to its intramolecular hydrogen bonding. In general, incorporating the pyridinium group into the biopolymer structure can destroy part of the hydrogen bonds, convert the amine group to imine, and affect the part of the antioxidant property of the 
TABLE 4: Overview of copper oxide biocomposite films' studies published as food packaging applications.

\begin{tabular}{|c|c|c|c|c|c|c|}
\hline Polymer + CuONPs & $\begin{array}{c}\text { CuONPs' } \\
\text { particle size }\end{array}$ & $\begin{array}{c}\text { Polymer + CuONPs' } \\
\text { particle size }\end{array}$ & $\begin{array}{l}\text { Cytotoxicity (cell } \\
\text { line- } \mathrm{IC}_{50} \text { ) }\end{array}$ & $\begin{array}{c}\text { Antimicrobial } \\
\text { activities' tested strains }\end{array}$ & $\begin{array}{c}\text { Antioxidant } \\
\text { activity (DPPH- } \\
\text { ABTS }\end{array}$ & Study \\
\hline CMC-CuO & $40-50 \mathrm{~nm}$ & $60-75 \mathrm{~nm}$ & Not reported & E. coli-S. aureus & Not reported & {$[147]$} \\
\hline Chitosan-CuO & Not reported & $10-25 \mathrm{~nm}$ & Not reported & E. coli-S. aureus & $\begin{array}{c}\text { Not reported } \\
\mathrm{DPPH}=92.55 \mu \mathrm{g} /\end{array}$ & [148] \\
\hline Chitosan & Not reported & Not reported & $\begin{aligned} & \mathrm{MCF}-7=29.73 \mu \mathrm{g} / \\
& \mathrm{mL}\end{aligned}$ & & $\begin{array}{c}\mathrm{mL} \\
\mathrm{ABTS}=92.06 \mu \mathrm{g} / \\
\mathrm{mL}\end{array}$ & \\
\hline $\mathrm{CuO}$ & $\begin{array}{l}\text { Crystal size: } \\
22 \mathrm{~nm}\end{array}$ & ------ & $\begin{array}{c}\mathrm{MCF}-7=28.82 \mu \mathrm{g} / \\
\mathrm{mL}\end{array}$ & & $\begin{array}{c}\mathrm{DPPH}=91.71 \mu \mathrm{g} / \\
\mathrm{mL} \\
\mathrm{ABTS}=91.05 \mu \mathrm{g} / \\
\mathrm{mL}\end{array}$ & \\
\hline Chitosan-CuO & - & Crystal size: $23 \mathrm{~nm}$ & $\begin{array}{c}\mathrm{MCF}-7=24.22 \mu \mathrm{g} / \\
\mathrm{mL}\end{array}$ & $\begin{array}{l}\text { E. coli, K. aerogenes- } \\
\text { S. aureus-S. pyogenes }\end{array}$ & $\begin{array}{c}\mathrm{DPPH}=90.03 \mu \mathrm{g} / \\
\mathrm{mL} \\
\mathrm{ABTS}=90.95 \mu \mathrm{g} / \\
\mathrm{mL}\end{array}$ & [56] \\
\hline Neem Seed-CuO & - & Crystal size: $82 \mathrm{~nm}$ & $\begin{aligned} & \mathrm{MCF}-7=93.83 \mu \mathrm{g} / \\
& \mathrm{mL}\end{aligned}$ & & $\begin{array}{c}\mathrm{DPPH}=88.03 \mu \mathrm{g} / \\
\mathrm{mL} \\
\mathrm{ABTS}=89.99 \mu \mathrm{g} / \\
\mathrm{mL}\end{array}$ & \\
\hline $\begin{array}{l}\text { Chitosan-copper } \\
\text { oxide-neem seed } \\
\text { (CS-CuO-NS) }\end{array}$ & - & Crystal size: $35 \mathrm{~nm}$ & $\begin{aligned} & \mathrm{MCF}-7=16.33 \mu \mathrm{g} / \\
& \mathrm{mL}\end{aligned}$ & & $\begin{array}{c}\mathrm{DPPH}=76.02 \mu \mathrm{g} / \\
\mathrm{mL} \\
\mathrm{ABTS}=88.53 \mu \mathrm{g} / \\
\mathrm{mL}\end{array}$ & \\
\hline $\begin{array}{l}\text { Chitosan-copper } \\
\text { oxide (CS-CuO) }\end{array}$ & $13-15 \mathrm{~nm}$ & $10-30 \mathrm{~nm}$ & $\begin{array}{c}\mathrm{A} 549=20 \pm 0.50 \mu \mathrm{g} / \\
\mathrm{mL}\end{array}$ & Not reported & Not reported & {$[57]$} \\
\hline $\begin{array}{l}\text { Terminalia catappa } \\
\text { leaf extract cellulose/ } \\
\mathrm{CuO}\end{array}$ & $21-40 \mathrm{~nm}$ & $10-60 \mathrm{~nm}$ & Not reported & E. coli & Not reported & {$[201]$} \\
\hline $\begin{array}{l}\text { CuO-bacterial } \\
\text { cellulose composite }\end{array}$ & Not reported & $50-100 \mathrm{~nm}$ & Not reported & E. coli-S. aureus & Not reported & {$[58]$} \\
\hline Chitosan-CuO & Not reported & $7 \pm 2 \mathrm{~nm}$ & Not reported & E. coli-S. aureus & Not reported & [202] \\
\hline $\begin{array}{l}\text { Starch-based } \\
\text { polyurethane/CuO } \\
\text { nanocomposite }\end{array}$ & Not reported & $47.51 \mathrm{~nm}$ & Not reported & $\begin{array}{l}\text { E. coli, S. aureus, } \\
\text { P. aeruginosa, } \\
\text { E. faecalis and } \\
\text { C. albicans }\end{array}$ & Not reported & [203] \\
\hline $\begin{array}{l}\text { Carboxymethyl } \\
\text { chitosan/CuO } \\
\text { nanocomposites } \\
\text { (CMCh/CuONPs) }\end{array}$ & Not reported & $20-50 \mathrm{~nm}$ & Not reported & E. coli-S. aureus & Not reported & {$[204]$} \\
\hline $\mathrm{BC}-\mathrm{CuO}$ & $\begin{array}{l}\text { Sonochemical } \\
\text { CuO crystal } \\
\text { size: } 43.52 \mathrm{~nm} \\
\text { Precipitation } \\
\text { CuO crystal } \\
\text { size: } 52.19 \mathrm{~nm}\end{array}$ & $\begin{array}{l}\text { Sonochemical BC } \\
\text { crystal size: } 1.67 \mathrm{~nm} \\
\text { Precipitation BC } \\
\text { crystal size: } 1.82 \mathrm{~nm}\end{array}$ & Not reported & E. coli-S. aureus & Not reported & [59] \\
\hline $\begin{array}{l}\text { Cellulose gum and } \\
\text { copper } \\
\text { nanoparticles-based } \\
\text { hydrogel (HCuNPs) }\end{array}$ & $7-12 \mathrm{~nm}$ & Not reported & $\begin{array}{c}\text { HeLa cells }=45 \mu \mathrm{g} / \\
\mathrm{mL}\end{array}$ & $\begin{array}{l}\text { K. pneumonia, E. coli, } \\
P . \text { aeruginosa, } \\
\text { S. aureus, P. vulgaris } \\
\text { and } P . \text { mirabilis }\end{array}$ & Not reported & {$[205]$} \\
\hline Chitosan-CuO & $50-60 \mathrm{~nm}$ & $58 \mathrm{~nm}$ & Not reported & Not reported & Not reported & [206] \\
\hline $\begin{array}{l}\text { Carrageenan and } \\
\text { copper } \\
\text { nanoparticles-based } \\
\text { hydrogels and films }\end{array}$ & Not reported & $150-200 \mathrm{~nm}$ & Not reported & $\begin{array}{c}\text { E. coli - } \\
\text { L. monocytogenes }\end{array}$ & Not reported & {$[172]$} \\
\hline Chitosan-CuNPs & $163 \mathrm{~nm}$ & $100-200 \mathrm{~nm}$ & Not reported & $\begin{array}{l}\text { P. aphanidermatum-R. } \\
\text { solani }\end{array}$ & Not reported & [207] \\
\hline Cellulose-CuNPs & $20-80 \mathrm{~nm}$ & $100 \mathrm{~nm}$ & Not reported & E. coli-Bacillus.sp & Not reported & [208] \\
\hline
\end{tabular}


TABLE 4: Continued.

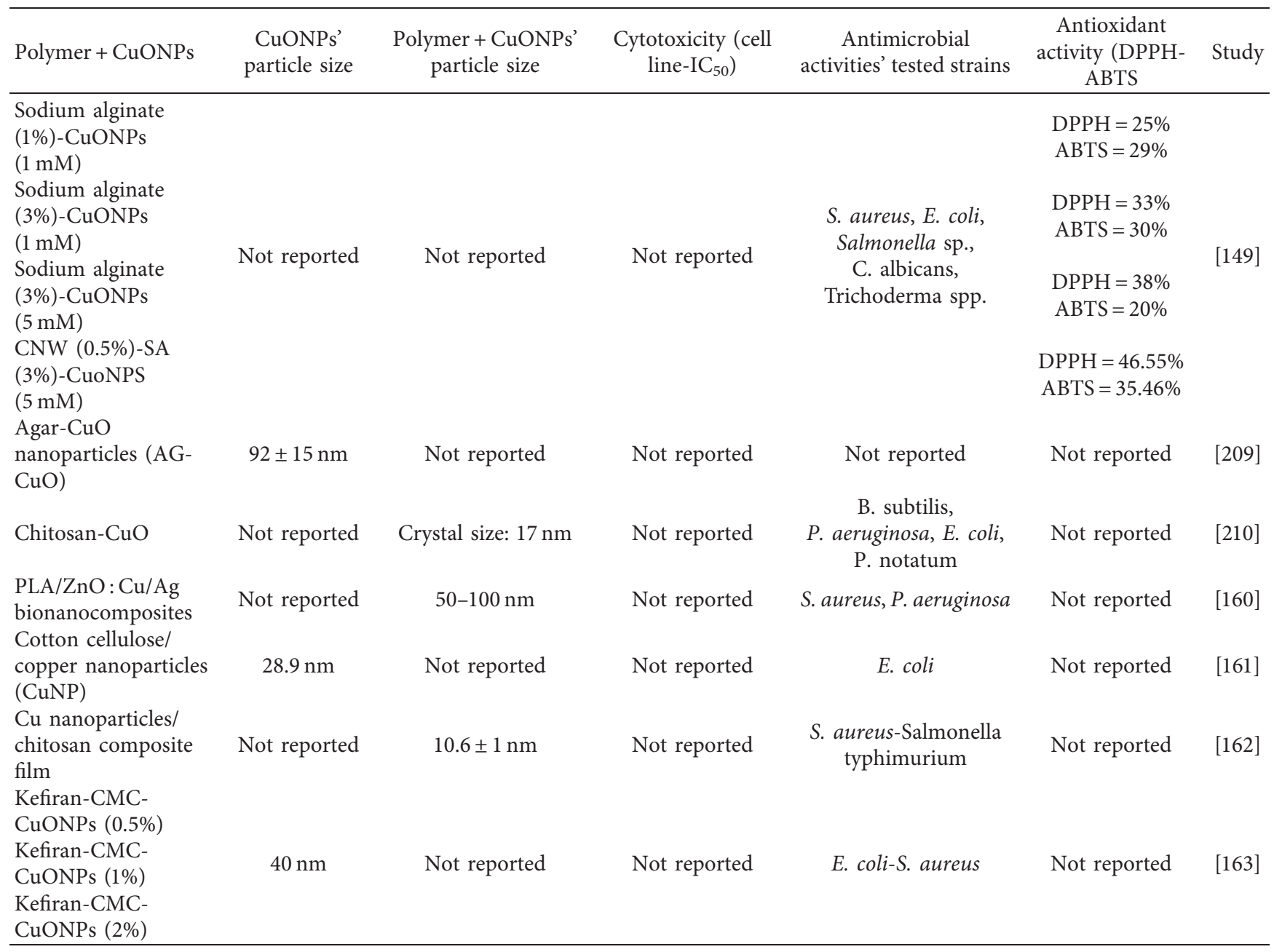

chitosan related to the amine group [211]. In chitosan, there are hydroxyl and amine groups that play an essential role in its antioxidant properties. However, intramolecular hydrogen bonds in the chitosan molecules reduce these two groups [212].

In the study by Saravanakumar et al. [37], they evaluated the DPPH and ABTS scavenging activity with four produced combination films with cellulose, sodium alginate (SA), and $\mathrm{CuO}$ nanoparticles with various concentrations. The $\mathrm{CNW}$ (0.5\%)-SA (3\%)-CuONPs ( $5 \mathrm{mM}$ ) film showed the highest $\mathrm{DPPH}$ and ABTS scavenging activity with $46.55 \%$ and $35.46 \%$ compared to other films, respectively. Active food packaging liberated copper oxide nanoparticles and CNW against ABTS and DPPH oxidation. Copper oxide nanoparticles and CNW are linked to the biopolymers' antioxidant properties [200,213] (Table 4).

The DPPH scavenging activity was estimated for sodium alginate (1\%)-CuONPs ( $1 \mathrm{mM})$, sodium alginate (3\%)CuONPs $(1 \mathrm{mM})$, and sodium alginate (3\%)-CuONPs $(5 \mathrm{mM})$ biopolymers with approximately $25 \%, 33 \%$, and $38 \%$, respectively. For ABTS, the scavenging activity calculated around $29 \%, 30 \%$, and $20 \%$ refers to sodium alginate (1\%)-CuONPs (1 mM), sodium alginate (3\%)-CuONPs
$(1 \mathrm{mM})$, and sodium alginate (3\%)-CuONPs $(5 \mathrm{mM})$ biopolymers, respectively (Table 4). Active food packaging released copper oxide nanoparticles and CNW against ABTS and DPPH oxidation. The antioxidant activity in the biopolymer is related to the concentration of copper oxide nanoparticles. Because of the increase in copper oxide nanoparticles' concentration, the released electrons are bound to the DPPH-free nitrogen atom [214, 215]. Overall, increasing the concentration of CuONPs increased DPPH scavenging inhibition and ABTS scavenging in this investigation.

The studies above clearly show that copper oxide nanoparticles have better antioxidant properties than edible films without nanoparticles. It can also be concluded from the above studies that as the concentration of copper oxide nanoparticles increased, its antioxidant property increased because their electrons transferred into the free site of the nitrogen atom and occupied it, and the inhibition rate increased.

3.6. Antimicrobial Activities in CuO-Carbohydrate Films. In food packaging, the development of microorganisms such as bacteria, fungus, yeast, and viruses is a serious problem. 
Using robust antimicrobial packaging can be the right solution for creating shelf life, quality, and food safety against pathogens that cause food to spoil $[216,217]$. Antimicrobial packaging is an active packaging type. In addition to its other beneficial properties, active packaging can play an essential role in controlling and preventing the growth of pathogens in the food packaging [218-220]. They naturally or artificially produce antimicrobial compounds in the packaging structure [221, 222]. Producing new packaging with natural antimicrobial compounds is a promising way to protect food and is one of the factors used today with nanoparticle coatings [223, 224]. Metal oxide nanoparticles are among minerals that have natural antimicrobial activity. This polymer-assisted ensures that the nanoparticles are evenly dispersed throughout the polymer matrix, impacting the films' thermal stability, mechanical strength, barrier properties, homogeneity, and antimicrobial properties [44]. This type of antimicrobial material has higher thermal stability than organic matter, having the same property. Therefore, metallic nanoparticles (MNP) are highly resistant to harsh conditions [73, 225]. One of these metal nanoparticles is copper oxide, which has been investigated for its antimicrobial properties in various biopolymers film in different studies [128, 135, 143, 145, 163, 205, 226, 227] (Tables 5 and 6).

Various studies have shown that chitosan as an edible film is combined with copper oxide nanoparticles and exhibits excellent antimicrobial properties. The authors concluded that the composition of copper oxide nanoparticles homogeneously in the edible film could play a role in this respect. To this end, they investigated the antimicrobial role of $\mathrm{CuO}$ nanocomposite biopolymers such as CMC, chitosan, cellulose, BC, alginate on the microorganisms of E. coli, $B$. subtilis, $S$. aureus, $K$. pneumonia, $P$. aeruginosa, $P$. Vulgaris, $P$. mirabilis, and $P$. chrysogenum ( $P$. notatum). Researchers examined the disc's antimicrobial properties in these studies and reported a growth inhibition rate.

Jayaramudu et al. [202] pointed to the antimicrobial role of this chitosan-CuONP biopolymer. The inhibition efficiency of the bacteria was measured after $48 \mathrm{~h}$ of growth at $37^{\circ} \mathrm{C}$. In this study, it was found that inhibition efficiency was in E. coli compared to Bacillus. They showed the $16 \mathrm{~mm}$ and $13 \mathrm{~mm}$ inhibition zone (IZ) for E.coli and Bacillus, respectively (Table 5). This report corroborates with other reports that copper oxide nanoparticles have more potent antimicrobial properties than copper nanoparticles [228, 229]. In vitro condition, Farhoudian et al. [148] demonstrated that the antibacterial activity of chitosan-CuO was recorded on Gram-negative bacteria (E. coli) and Gram-positive (S. aureus) by the disk diffusion test. They presented the 6-11 $\mathrm{mm}$ and $6-8 \mathrm{~mm}$ inhibition zone for E.coli and S. aureus, respectively, for chitosan-CuO at different times (Table 4).

Logpriya et al. [210] presented similar results to Farhoudian et al. They examined the antimicrobial activity of chi- $\mathrm{CuO}$ at 25,50 , and $100 \mu \mathrm{L}$. They showed the IZs for E. coli at $25 \mu \mathrm{Land} 50 \mu \mathrm{L}$ to be $6 \mathrm{~mm}$, and at $100 \mu \mathrm{L}$ to be $8 \mathrm{~mm}$. The IZs for B. subtilis, $P$. aeruginosa, and $P$. notatum at 25,50 , and $100 \mu \mathrm{L}$ concentrations were $6.5,7,8 \mathrm{~mm} ; 6,6.5$,
$8 \mathrm{~mm}$; and 0, 10, $10 \mathrm{~mm}$, respectively (Table 5). From their study, it can be concluded that antimicrobial activity increased with an increase in the concentration of chitosan$\mathrm{CuO}$ biopolymer. The antimicrobial activity usually depends on the size and shape of the copper oxide nanoparticles [230]. Another study showed that copper oxide nanocomposites with biopolymer coatings had a potent antimicrobial activity [231]. Due to its many hydroxyl and amine groups, chitosan has a high affinity to metal ions, leading to the formation of chitosan-copper oxide nanocomposites [232].

In another study [56], the antimicrobial properties of chitosan, $\mathrm{CuO}$, chitosan- $\mathrm{CuO}$, neem seed-CuO, and chi$\mathrm{CuO}-\mathrm{NS}$ biocomposites were investigated. This examination reviewed these nanocomposites' antimicrobial properties on two significant strains of Gram-positive pathogenic bacteria, $S$. aureus, S. pyogenes, and two strains of Gram-negative bacteria $E$. coli and $K$ aerogenes by agar well diffusion (Table 5). The chi-CuO-NS showed the highest antimicrobial activity against $S$. aureus with a $23-\mathrm{mm}$ inhibition zone among these nanocomposite films, followed by $E$. coli, S. pyogenes, and K. aerogenes showing 22-, 21-, and 20-mm inhibition zones, respectively. NS-CuO's next film represented $20 \mathrm{~mm}$ IZ for S. aureus, followed by S. pyogenes, $K$. aerogenes, and E. coli with $19 \mathrm{~mm}, 19 \mathrm{~mm}$, and $18 \mathrm{~mm}$, respectively. Chitosan-CuO calculated a $19 \mathrm{~mm}$ inhibition zone for S. aureus, followed by E. coli, S. pyogenes, and $K$. aerogenes with 18,18 , and $17 \mathrm{~mm}$ inhibition zone, respectively. The $\mathrm{CuO}$ nanoparticle individually showed the $17 \mathrm{~mm}$ inhibition zone for $S$. aureus; and then, $16 \mathrm{~mm}$, $16 \mathrm{~mm}$, and $15 \mathrm{~mm}$ inhibition zone for E. coli, S. pyogenes, and $K$. aerogenes, respectively. Finally, chitosan showed moderate antimicrobial activity against $S$. aureus with a $15 \mathrm{~mm}$ inhibition zone, followed by $14 \mathrm{~mm}, 13 \mathrm{~mm}$, and $12 \mathrm{~mm} \mathrm{IZ}$ for S. pyogenes, E. coli, and $K$. aerogenes, respectively, compared to other nanocomposites. From this study, it can be concluded that chitosan, $\mathrm{CuO}$, chitosan$\mathrm{CuO}$, neem seed-CuO, and chi-CuO-NS biocomposites confirmed a zone of inhibition against four pathogens in the order $S$. aureus $>E$. coli $>S$. pyogenes $>K$. aerogenes, respectively (Table 5). In this study, MIC and MBC tests were performed for $S$. aureus. Table 6 shows all the nanocomposites synthesized against this bacterium. It can be deduced from this table that the CS-CuO-NS biocomposite increased the antimicrobial activity at concentrations of 25 to $100 \mu \mathrm{g} / \mathrm{mL}$. In addition to the previously mentioned reason $[40,41]$, there is another possibility for bacteriolysis, which is the production of reactive oxygen species (ROS) due to metal oxide [215]. The ROS interact with the microbial cell membrane, which leads to cell lysis and bacteria death. Reactive oxygen species contact the bacterial membrane and cause lysis and bacterial death [215].

Al-Enizi AM et al. [205] showed the inhibition zone against UTI pathogens (E.coli, S. aureus, K. pneumonia, $P$. aeruginosa, $P$. Vulgaris, and $P$. mirabilis) (Table 5). Their study investigated antimicrobial activity for CuNPs-CMC hydrogel at three concentrations $1 \%, 3 \%$, and $5 \%$, respectively. The IZ for E. coli demonstrated 12, 13.6, and $15.2 \mathrm{~mm}$ at $1 \%, 3 \%$, and $5 \%$ concentration, respectively. For S. aureus, 
TABLE 5: Inhibition zone of food-borne pathogens in CuONPs biopolymer films used for antimicrobial packaging.

\begin{tabular}{|c|c|c|c|}
\hline Microorganisms & Sample & Inhibition zone (mm) & Study \\
\hline $\begin{array}{l}\text { E. coli } \\
\text { S. aureus }\end{array}$ & $\mathrm{CMC}-\mathrm{CuO}$ & $\begin{array}{c}9-14 \\
15-19 \\
\end{array}$ & {$[147]$} \\
\hline $\begin{array}{l}\text { E. coli } \\
\text { S. aureus }\end{array}$ & Chi-CuO & $\begin{array}{c}6-11 \\
6-8 \\
\end{array}$ & [148] \\
\hline $\begin{array}{l}\text { E. coli } \\
\text { K. aerogenes } \\
\text { S. pyogenes } \\
\text { S. aureus } \\
\text { E. coli } \\
\text { K. aerogenes } \\
\text { S. pyogenes } \\
\text { S. aureus } \\
\text { E. coli } \\
\text { K. aerogenes } \\
\text { S. pyogenes } \\
\text { S. aureus } \\
\text { E. coli } \\
\text { K. aerogenes } \\
\text { S. pyogenes } \\
\text { S. aureus } \\
\text { E. coli } \\
\text { K. aerogenes } \\
\text { S. pyogenes } \\
\text { S. aureus } \\
\end{array}$ & $\begin{array}{l}\text { Chi-CuO-NS } \\
\text { NS-CuO } \\
\text { Chi-CuO } \\
\text { CuO }\end{array}$ & $\begin{array}{l}2 \\
23 \\
20 \\
21 \\
18 \\
19 \\
19 \\
20 \\
18 \\
17 \\
18 \\
19 \\
16 \\
15 \\
16 \\
17 \\
13 \\
12 \\
14 \\
15 \\
\end{array}$ & {$[56]$} \\
\hline E. coli & Cellulose-CuO & $\begin{array}{c}2(5 \mathrm{mM}) \\
5(25 \mathrm{mM}) \\
10(125 \mathrm{mM}) \\
12(250 \mathrm{mM}) \\
\end{array}$ & {$[201]$} \\
\hline $\begin{array}{l}\text { E. coli } \\
\text { S. aureus }\end{array}$ & $\mathrm{BC}-\mathrm{CuO}$ & $\begin{array}{c}11.08(\mathrm{pH}=7) \\
10.01(\mathrm{pH}=8) \\
8.90(\mathrm{pH}=9) \\
8.67(\mathrm{pH}=10) \\
7.62(\mathrm{pH}=11) \\
23.53(\mathrm{pH}=7) \\
22.57(\mathrm{pH}=8) \\
21.23(\mathrm{pH}=9) \\
19.42(\mathrm{pH}=10) \\
16.74(\mathrm{pH}=11) \\
\end{array}$ & {$[58]$} \\
\hline $\begin{array}{l}\text { E. coli } \\
\text { Bacillus } \\
\text { E. coli } \\
\text { Bacillus } \\
\text { E. coli } \\
\text { Bacillus } \\
\text { E. coli } \\
\text { Bacillus } \\
\end{array}$ & $\begin{array}{c}\text { Chi-Cu } \\
\text { Chi-CuO } \\
\text { Chi-Cu-Chi } \\
\text { Chi-CuO-chi }\end{array}$ & $\begin{array}{c}14 \\
9 \\
16 \\
13 \\
6 \\
5 \\
10 \\
7.5 \\
\end{array}$ & [202] \\
\hline $\begin{array}{l}\text { E. coli } \\
\text { S. aureus }\end{array}$ & $\begin{array}{l}\mathrm{BC}-\mathrm{CuO} \text { sonochemical } \\
\mathrm{BC}-\mathrm{CuO} \text { precipitation } \\
\mathrm{BC}-\mathrm{CuO} \text { sonochemical } \\
\mathrm{BC}-\mathrm{CuO} \text { precipitation }\end{array}$ & $\begin{array}{l}5.71 \pm 0.65 \\
6.33 \pm 0.44 \\
9.37 \pm 0.97 \\
5.21 \pm 0.22 \\
\end{array}$ & [59] \\
\hline
\end{tabular}


TABle 5: Continued.

\begin{tabular}{|c|c|c|c|}
\hline Microorganisms & Sample & Inhibition zone $(\mathrm{mm})$ & Study \\
\hline \multirow{3}{*}{ E. coli } & CuNPs-CMC hydrogel (1.0) & 12 & \multirow{18}{*}{ [205] } \\
\hline & CuNPs-CMC hydrogel (3.0) & 13.6 & \\
\hline & CuNPs-CMC hydrogel (5.0) & 15.2 & \\
\hline \multirow{3}{*}{ S. aureus } & CuNPs-CMC hydrogel (1.0) & 12.2 & \\
\hline & CuNPs-CMC hydrogel (3.0) & 14 & \\
\hline & CuNPs-CMC hydrogel (5.0) & 15.6 & \\
\hline \multirow{3}{*}{ K. pneumonia } & CuNPs-CMC hydrogel (1.0) & 11.4 & \\
\hline & CuNPs-CMC hydrogel (3.0) & 13.2 & \\
\hline & CuNPs-CMC hydrogel (5.0) & 15.2 & \\
\hline \multirow{3}{*}{$P$. aeruginosa } & CuNPs-CMC hydrogel (1.0) & 12.8 & \\
\hline & CuNPs-CMC hydrogel (3.0) & 14 & \\
\hline & CuNPs-CMC hydrogel (5.0) & 16.4 & \\
\hline \multirow{3}{*}{ P. vulgaris } & CuNPs-CMC hydrogel (1.0) & 12 & \\
\hline & CuNPs-CMC hydrogel (3.0) & 13.8 & \\
\hline & CuNPs-CMC hydrogel (5.0) & 15.8 & \\
\hline \multirow{3}{*}{ P. mirabilis } & CuNPs-CMC hydrogel (1.0) & 12.4 & \\
\hline & CuNPs-CMC hydrogel (3.0) & 14 & \\
\hline & CuNPs-CMC hydrogel (5.0) & 15.8 & \\
\hline \multirow{4}{*}{ E. coli } & Cellulose-CuNPs (5 mM) & 0 & \multirow{6}{*}{ [208] } \\
\hline & Cellulose-CuNPs (25 mM) & 0 & \\
\hline & Cellulose-CuNPs (125 mM) & 9 & \\
\hline & Cellulose-CuNPs (250 mM) & 12 & \\
\hline \multirow{2}{*}{ Bacillus } & Cellulose-CuNPs (250 mM) & 29 & \\
\hline & Cellulose-CuNPs (500 mM) & 32 & \\
\hline \multirow{4}{*}{ E. coli } & SA (1\%)-CuONPs (1 mM) & $5.20 \pm 0.54$ & \multirow{20}{*}{ [149] } \\
\hline & SA (3\%)-CuONPs $(1 \mathrm{mM})$ & $5.58 \pm 0.85$ & \\
\hline & SA $(3 \%)-C u O N P s(5 \mathrm{mM})$ & $8.72 \pm 0.15$ & \\
\hline & CNW (0.5\%)-SA (3\%)-CuONPs (5 mM) & $12.12 \pm 0.58$ & \\
\hline \multirow{4}{*}{ S. aureus } & SA $(1 \%)-C u O N P s(1 \mathrm{mM})$ & $21.65 \pm 0.62$ & \\
\hline & SA (3\%)-CuONPs (1 mM) & $12.25 \pm 0.84$ & \\
\hline & SA (3\%)-CuONPs $(5 \mathrm{mM})$ & $17.18 \pm 0.45$ & \\
\hline & CNW (0.5\%)-SA (3\%)-CuONPs (5 mM) & $27.49 \pm 0.91$ & \\
\hline \multirow{4}{*}{ Salmonella spp. } & SA $(1 \%)-C u O N P s(1 \mathrm{mM})$ & $12.12 \pm 0.15$ & \\
\hline & SA (3\%)-CuONPs (1 mM) & $18.12 \pm 0.64$ & \\
\hline & SA $(3 \%)-C u O N P s(5 m M)$ & $24.25 \pm 0.48$ & \\
\hline & CNW (0.5\%)-SA (3\%)-CuONPs (5 mM) & $25.21 \pm 1.05$ & \\
\hline \multirow{4}{*}{ C. albicans } & SA (1\%)-CuONPs $(1 \mathrm{mM})$ & $22.23 \pm 0.19$ & \\
\hline & SA (3\%)-CuONPs (1 mM) & $17.25 \pm 0.17$ & \\
\hline & SA (3\%)-CuONPs $(5 \mathrm{mM})$ & $21.26 \pm 0.32$ & \\
\hline & CNW (0.5\%)-SA (3\%)-CuONPs (5 mM) & $23.35 \pm 0.45$ & \\
\hline \multirow{4}{*}{ Trichoderma spp. } & SA (1\%)-CuONPs $(1 \mathrm{mM})$ & $2.50 \pm 0.68$ & \\
\hline & SA (3\%)-CuONPs (1 mM) & $3.63 \pm 0.62$ & \\
\hline & SA (3\%)-CuONPs $(5 \mathrm{mM})$ & $4.63 \pm 0.53$ & \\
\hline & CNW (0.5\%)-SA (3\%)-CuONPs (5 mM) & $5.31 \pm 1.16$ & \\
\hline \multirow{3}{*}{ E. coli } & Chi-CuO $(25 \mu \mathrm{L})$ & $6 \pm 0.5$ & \multirow{12}{*}[210]{} \\
\hline & Chi-CuO $(50 \mu \mathrm{L})$ & $6 \pm 0.5$ & \\
\hline & Chi-CuO $(100 \mu \mathrm{L})$ & $8 \pm 0.5$ & \\
\hline \multirow{3}{*}{ B. subtilis } & Chi-CuO $(25 \mu \mathrm{L})$ & $6.5 \pm 0.5$ & \\
\hline & Chi-CuO $(50 \mu \mathrm{L})$ & $7 \pm 0.5$ & \\
\hline & Chi-CuO $(100 \mu \mathrm{L})$ & $8 \pm 0.5$ & \\
\hline & Chi-CuO $(25 \mu \mathrm{L})$ & $6 \pm 0.5$ & \\
\hline$P$. aeruginosa & Chi-CuO $(50 \mu \mathrm{L})$ & $6.5 \pm 0.5$ & \\
\hline & Chi-CuO $(100 \mu \mathrm{L})$ & $8 \pm 0.5$ & \\
\hline & Chi-CuO $(25 \mu \mathrm{L})$ & Not reported & \\
\hline P. notatum & Chi-CuO $(50 \mu \mathrm{L})$ & $10 \pm 0.5$ & \\
\hline & Chi-CuO $(100 \mu \mathrm{L})$ & $10 \pm 0.5$ & \\
\hline
\end{tabular}




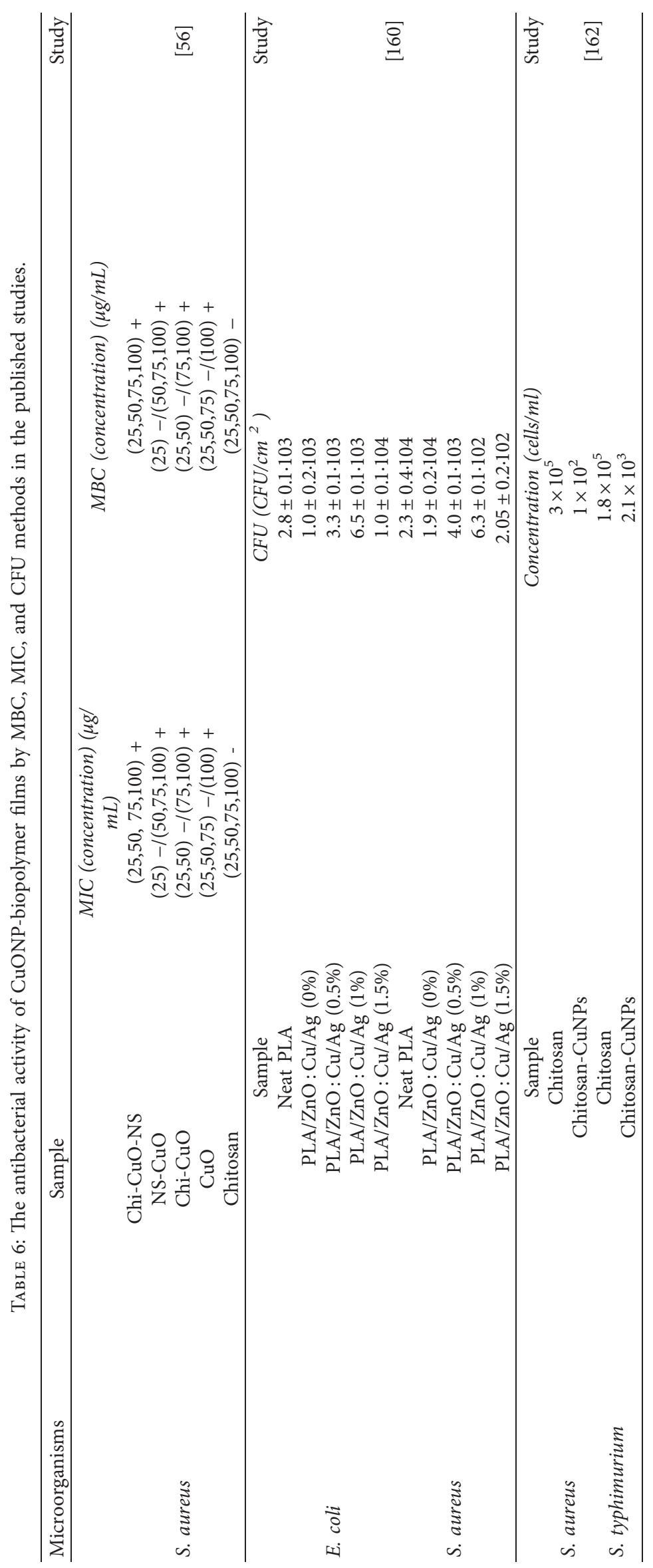




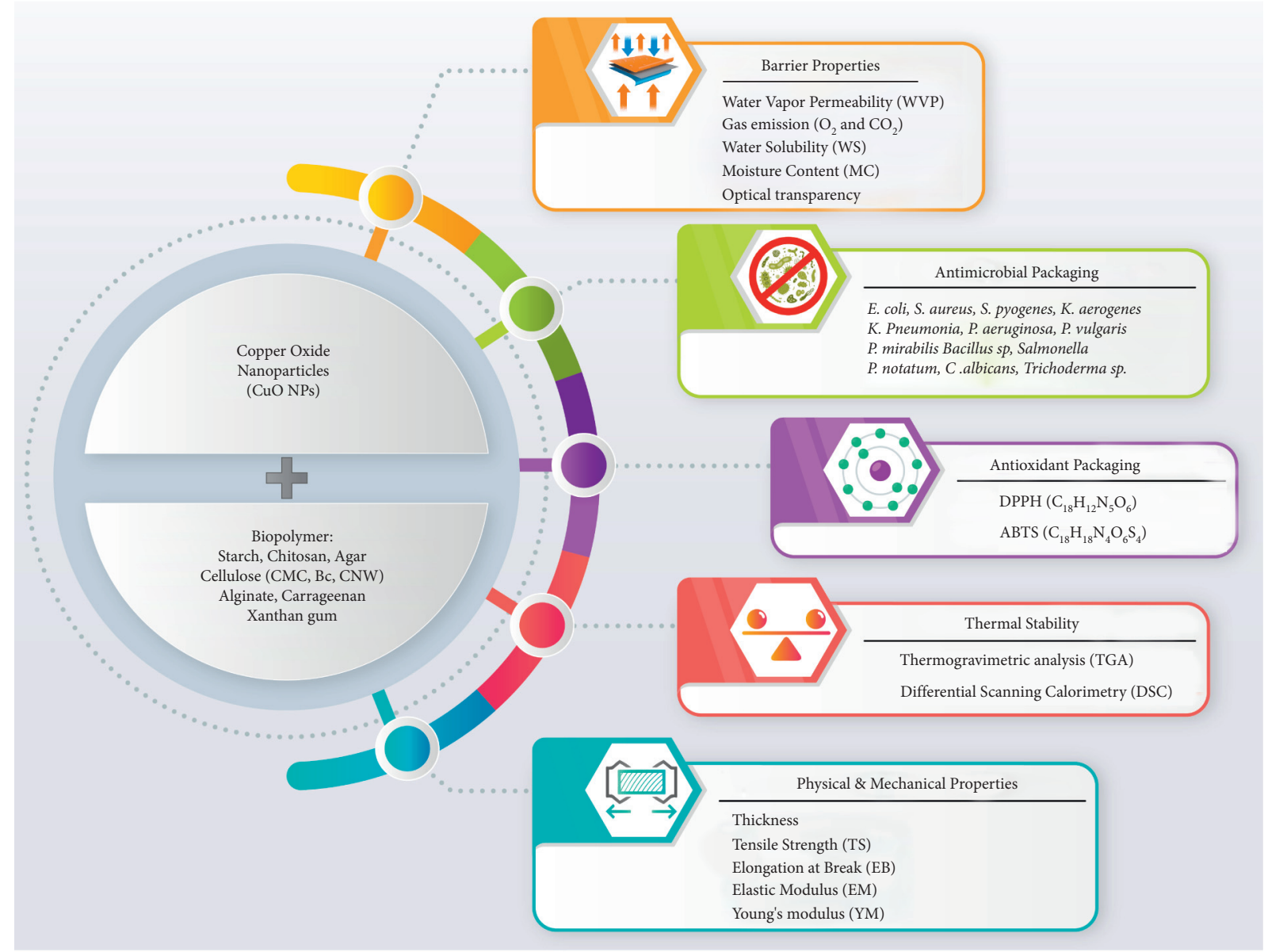

Figure 1: Advantageous effects of copper oxide nanoparticles on the physical, mechanical, barrier, thermal stability, antioxidant, and antimicrobial properties of carbohydrate-based films in food nanopackaging.

IZ was $12.2,14$, and $15.6 \mathrm{~mm}$ at $1 \%, 3 \%$, and $5 \%$ CuNPsCMC hydrogel concentrations, respectively. For $K$. pneumonia at the same order of concentrations, IZ was $11.4,13.2$, and $15.2 \mathrm{~mm}$, respectively. The inhibition zone for P. aeruginosa was $12.8,14$, and $16.4 \mathrm{~mm}$ at $1 \%, 3 \%$, and $5 \%$ CuNPs-CMC hydrogel concentration, respectively. P. Vulgaris showed the $12 \mathrm{~mm}, 13.8 \mathrm{~mm}$, and $15.8 \mathrm{~mm}$ inhibition at the same order of concentrations, respectively. For P. mirabilis, the inhibition zone was showed $12.8 \mathrm{~mm}$, $14 \mathrm{~mm}$, and $15.8 \mathrm{~mm}$ at $1 \%, 3 \%$, and 5\% CuNPs-CMC hydrogel concentrations, respectively (Table 5).

CMC-CuO demonstrated a comparable antibacterial activity on E. coli and $S$. aureus in research by Yadollahi et al. [147]. E. coli displayed a 9-14 $\mathrm{mm}$ inhibition zone at varying doses, whereas $S$. aureus showed a $15-19 \mathrm{~mm}$ inhibition zone (Table 5). The results show that the nanocomposite hydrogel with copper oxide was more toxic to the bacteria under the same conditions than pure hydrogel. The study also showed that nanocomposite hydrogels' antimicrobial efficiency, regarding the bacterial type, was affected by the concentration of copper oxide nanoparticles because the hydrogels with higher nanoparticles showed significant antimicrobial properties.
To investigate the antimicrobial properties of celluloseCuNPs, Muthulakshmi and her colleagues [201] experimented on E. coli bacteria (Table 5). Antimicrobial activity tests were also performed on cellulose-free nanoparticles (as control). Antimicrobial results were assessed on control samples and cellulose- $\mathrm{Cu}$ nanocomposites for concentrations of $5 \mathrm{mM}$, $25 \mathrm{mM}, 125 \mathrm{mM}$, and $250 \mathrm{mM}$ of copper sulfate solution. Although the control sample showed no antimicrobial activity, all the copper nanoparticle biocomposites had significant antimicrobial properties. For concentrations of $5 \mathrm{mM}, 25 \mathrm{mM}$, $125 \mathrm{mM}$, and $250 \mathrm{mM}$ of copper sulfate solution, they obtained inhibitory zones of $2 \mathrm{~mm}, 5 \mathrm{~mm}, 10 \mathrm{~mm}$, and $12 \mathrm{~mm}$ for cellulose- $\mathrm{Cu}$ nanocomposites (Table 5).

In another study by Muthulakshmi and her colleagues [208], they reported the potential inhibition of the celluloseCuNP nanocomposite films at $250 \mu \mathrm{g} / \mathrm{ml}$ and $500 \mu \mathrm{g} / \mathrm{ml}$ of CuNP in the matrix against Bacillus and four concentrations against E. coli strains. The cellulose-CuNP (250 mM) nanobiocomposite shows the highest inhibition rate by $12 \mathrm{~mm}$ for E. coli. After that, $125 \mathrm{mM}$ concentration showed the $9 \mathrm{~mm}$ inhibition zone. For cellulose-CuNP, $5 \mathrm{mM}$ and $25 \mathrm{mM}$ concentrations did not show any IZ against E. coli bacteria (Table 5). 
Two concentrations of cellulose-CuNP, $250 \mathrm{mM}$ and $500 \mathrm{mM}$, were considered for antimicrobial activity against Bacillus bacteria. The results demonstrated a $29 \mathrm{~mm}$ and a $32 \mathrm{~mm}$ inhibition zone for zone clearance for celluloseCuNP (250 mM) and cellulose-CuNP (500 mM).

\section{Conclusion}

One of the most pressing challenges today is to remove or reduce the amount of plastic that is most damaging to the environment. Biopolymers for biodegradable and alternative plastics have been the subject of substantial research in recent years. Biopolymers can help to reduce waste by reducing the usage of synthetic and chemical compounds. However, biopolymers alone have mechanical, thermal stability, antimicrobial, and antioxidant properties. Nanotechnology nowadays comes with the help of biopolymers to enhance their physical, mechanical, and barrier properties. Copper nanoparticles and their derivatives are among the most critical nanoparticles in this study (Figure 1). The combination of copper nanoparticles with biopolymers increases their mechanical properties (such as tensile properties and flexibility) and improves their barrier properties (such as water vapor permeability, oxygen gas, and carbon dioxide emissions). Improving barrier properties can play an essential role in active food packaging. Combining copper nanoparticles with biopolymers reduces oxygen penetration in food packaging. It prevents aerobic bacteria's growth under anaerobic conditions, thus having a potent antimicrobial property that synthetic products such as plastics lack. On the other hand, reducing oxygen levels does not cause the compounds of active oxygen species to impair the food's antioxidant properties. However, further studies are needed on the role of copper nanoparticles and their derivatives with biodegradable biopolymers to find a more suitable option for active packaging without causing toxicity and endangering the environment and human health.

\section{Data Availability}

There are no primary raw data associated with this review.

\section{Conflicts of Interest}

The authors declare that they have no conflicts of interest.

\section{Authors' Contributions}

M. Mesgari and A. H. Aalami have equal contribution as the first author of this article.

\section{References}

[1] R. Kognole, K. Shipkule, M. Patil, L. Patil, and U. Survase, Utilization of Plastic Waste for Making Plastic Bricks, 2019.

[2] J. Wróblewska-Krepsztul, T. Rydzkowski, G. Borowski, M. Szczypiński, T. Klepka, and V. K. Thakur, "Recent progress in biodegradable polymers and nanocompositebased packaging materials for sustainable environment,"
International Journal of Polymer Analysis and Characterization, vol. 23, no. 4, pp. 383-395, 2018.

[3] S. Collazo-Bigliardi, R. Ortega-Toro, and A. Chiralt, Properties of Micro-and Nano-Reinforced Biopolymers for Food applications. Polymers for Food Applications, Springer, Berlin, Germany, 2018.

[4] S. F. Hosseini, M. Rezaei, M. Zandi, and F. Farahmandghavi, "Development of bioactive fish gelatin/chitosan nanoparticles composite films with antimicrobial properties," Food Chemistry, vol. 194, pp. 1266-1274, 2016.

[5] D. Dehnad, Z. Emam-Djomeh, H. Mirzaei, S.-M. Jafari, and S. Dadashi, "Optimization of physical and mechanical properties for chitosan-nanocellulose biocomposites," Carbohydrate Polymers, vol. 105, pp. 222-228, 2014.

[6] D. Piñeros-Hernandez, C. Medina-Jaramillo, A. LópezCórdoba, and S. Goyanes, "Edible cassava starch films carrying rosemary antioxidant extracts for potential use as active food packaging," Food Hydrocolloids, vol. 63, pp. 488-495, 2017.

[7] R. Sothornvit, "Nanostructured materials for food packaging systems: new functional properties," Current Opinion in Food Science, vol. 34, 2019.

[8] K. Kraśniewska, S. Galus, and M. Gniewosz, "Biopolymersbased materials containing silver nanoparticles as active packaging for food applications-A review," International Journal of Molecular Sciences, vol. 21, no. 3, p. 698, 2020.

[9] A. Bahrami, R. Delshadi, E. Assadpour, S. M. Jafari, and L. Williams, "Antimicrobial-loaded nanocarriers for food packaging applications," Advances in Colloid and Interface Science, vol. 278, Article ID 102140, 2020.

[10] C. López-de-Dicastillo, J. Gómez-Estaca, R. Catalá, R. Gavara, and P. Hernández-Muñoz, "Active antioxidant packaging films: development and effect on lipid stability of brined sardines," Food Chemistry, vol. 131, no. 4, pp. 13761384, 2012.

[11] C. Medina Jaramillo, T. J. Gutiérrez, S. Goyanes, C. Bernal, and L. Famá, "Biodegradability and plasticizing effect of yerba mate extract on cassava starch edible films," Carbohydrate Polymers, vol. 151, pp. 150-159, 2016.

[12] W. Tongdeesoontorn, L. J. Mauer, S. Wongruong, P. Sriburi, A. Reungsang, and P. Rachtanapun, "Antioxidant films from cassava starch/gelatin biocomposite fortified with quercetin and TBHQ and their applications in food models," Polymers, vol. 13, no. 7, p. 1117, 2021.

[13] H. Archana, C. Chellaram, and T. P. Anand, "Impact of marine nanoparticles for sustained drug delivery-a review," 2013.

[14] C. Chellaram, G. Murugaboopathi, A. A. John et al., "Significance of nanotechnology in food industry," $A P C B E E$ procedia, vol. 8, pp. 109-113, 2014.

[15] P. Jamdagni, P. Khatri, and J. S. Rana, "Green synthesis of zinc oxide nanoparticles using flower extract of Nyctanthes arbor-tristis and their antifungal activity," Journal of King Saud University Science, vol. 30, no. 2, pp. 168-175, 2018.

[16] M. A. Syed, "Advances in nanodiagnostic techniques for microbial agents," Biosensors and Bioelectronics, vol. 51, pp. 391-400, 2014.

[17] D. Bobo, K. J. Robinson, J. Islam, K. J. Thurecht, and S. R. Corrie, "Nanoparticle-based medicines: a review of FDA-approved materials and clinical trials to date," Pharmaceutical Research, vol. 33, no. 10, pp. 2373-2387, 2016.

[18] G. Chen, I. Roy, C. Yang, and P. N. Prasad, "Nanochemistry and nanomedicine for nanoparticle-based diagnostics and 
therapy," Chemical Reviews, vol. 116, no. 5, pp. 2826-2885, 2016.

[19] A. H. Aalami, M. Mesgari, and A. Sahebkar, "Synthesis and characterization of green zinc oxide nanoparticles with antiproliferative effects through apoptosis induction and microRNA modulation in breast cancer cells," Bioinorganic Chemistry and Applications, vol. 2020, Article ID 8817110, 2020.

[20] N. Alizadeh and S. Malakzadeh, "Antioxidant, antibacterial and anti-cancer activities of $\beta$-and $\gamma$-CDs/curcumin loaded in chitosan nanoparticles," International Journal of Biological Macromolecules, vol. 147, pp. 778-791, 2020.

[21] A. L. Sánchez-López, Y. Perfecto-Avalos, A. Sanchez-Martinez, O. Ceballos-Sanchez, M. Sepulveda-Villegas, and G. Rincón-Enríquez, "Influence of erbium doping on zinc oxide nanoparticles: structural, optical and antimicrobial activity," Applied Surface Science, vol. 575, Article ID 151764, 2022.

[22] A. Baschieri and R. Amorati, "Methods to determine chainbreaking antioxidant activity of nanomaterials beyond DPPH. A review," Antioxidants, vol. 10, no. 10, p. 1551, 2021.

[23] Z. Yu, Y. Tan, S. Luo et al., "Food nanoparticles from rice vinegar: isolation, characterization, and antioxidant activities," Npj Science of Food, vol. 6, no. 1, pp. 1-8, 2022.

[24] A. Diallo, B. D. Ngom, E. Park, and M. Maaza, "Green synthesis of $\mathrm{ZnO}$ nanoparticles by Aspalathus linearis: structural \& optical properties," Journal of Alloys and Compounds, vol. 646, pp. 425-430, 2015.

[25] B. T. Sone, E. Manikandan, A. Gurib-Fakim, and M. Maaza, "Sm2O3 nanoparticles green synthesis via Callistemon viminalis' extract," Journal of Alloys and Compounds, vol. 650, pp. 357-362, 2015.

[26] A. Eslami, M. M. Amini, A. R. Yazdanbakhsh, A. MohseniBandpei, A. A. Safari, and A. Asadi, "N,S co-doped TiO2nanoparticles and nanosheets in simulated solar light for photocatalytic degradation of non-steroidal anti-inflammatory drugs in water: a comparative study," Journal of Chemical Technology and Biotechnology, vol. 91, no. 10, pp. 2693-2704, 2016.

[27] P. J. P. Espitia, C. G. Otoni, and N. F. F. Soares, Zinc Oxide Nanoparticles for Food Packaging applications. Antimicrobial Food Packaging, Elsevier, Amsterdam, Netherlands, 2016.

[28] A. Weir, P. Westerhoff, L. Fabricius, K. Hristovski, and N. Von Goetz, "Titanium dioxide nanoparticles in food and personal care products," Environmental Science and Technology, vol. 46, no. 4, pp. 2242-2250, 2012.

[29] M. Das, N. Saxena, and P. D. Dwivedi, "Emerging trends of nanoparticles application in food technology: safety paradigms," Nanotoxicology, vol. 3, no. 1, pp. 10-18, 2009.

[30] T. Krivorotova, A. Cirkovas, S. Maciulyte et al., "Nisinloaded pectin nanoparticles for food preservation," Food Hydrocolloids, vol. 54, pp. 49-56, 2016.

[31] L. Rashidi and K. Khosravi-Darani, "The applications of nanotechnology in food industry," Critical Reviews in Food Science and Nutrition, vol. 51, no. 8, pp. 723-730, 2011.

[32] M. Hoseinnejad, S. M. Jafari, and I. Katouzian, "Inorganic and metal nanoparticles and their antimicrobial activity in food packaging applications," Critical Reviews in Microbiology, vol. 44, no. 2, pp. 161-181, 2018.

[33] V. K. Yemmireddy and Y.-C. Hung, "Selection of photocatalytic bactericidal titanium dioxide ( $\mathrm{TiO} 2)$ nanoparticles for food safety applications," Lebensmittel-Wissenschaft und -Technologie- Food Science and Technology, vol. 61, no. 1, pp. 1-6, 2015.
[34] C. Ma, J. C. White, J. Zhao, Q. Zhao, and B. Xing, "Uptake of engineered nanoparticles by food crops: characterization, mechanisms, and implications," Annual review of food science and technology, vol. 9, no. 1, pp. 129-153, 2018.

[35] J. Sarfraz, T. Gulin-Sarfraz, J. Nilsen-Nygaard, and M. K. Pettersen, "Nanocomposites for food packaging applications: an overview," Nanomaterials, vol. 11, no. 1, p. 10, 2021.

[36] K. Saravanakumar, A. Sathiyaseelan, A. V. A. Mariadoss, H. Xiaowen, and M.-H. Wang, "Physical and bioactivities of biopolymeric films incorporated with cellulose, sodium alginate and copper oxide nanoparticles for food packaging application," International Journal of Biological Macromolecules, vol. 153, pp. 207-214, 2020.

[37] S. H. Kamarudin, M. Rayung, F. Abu et al., "A review on antimicrobial packaging from biodegradable polymer composites," Polymers, vol. 14, no. 1, p. 174, 2022.

[38] Y.-Y. Xie, X.-H. Hu, Y.-W. Zhang et al., "Development and antibacterial activities of bacterial cellulose/graphene oxide$\mathrm{CuO}$ nanocomposite films," Carbohydrate Polymers, vol. 229, Article ID 115456, 2020.

[39] H. Almasi, P. Jafarzadeh, and L. Mehryar, "Fabrication of novel nanohybrids by impregnation of $\mathrm{CuO}$ nanoparticles into bacterial cellulose and chitosan nanofibers: characterization, antimicrobial and release properties," Carbohydrate Polymers, vol. 186, pp. 273-281, 2018.

[40] A. Errokh, A. M. Ferraria, D. S. Conceição et al., "Controlled growth of $\mathrm{Cu} 2 \mathrm{O}$ nanoparticles bound to cotton fibres," Carbohydrate Polymers, vol. 141, pp. 229-237, 2016.

[41] C. V. Garcia, G. H. Shin, and J. T. Kim, "Metal oxide-based nanocomposites in food packaging: applications, migration, and regulations," Trends in Food Science \& Technology, vol. 82, pp. 21-31, 2018.

[42] N. A. Al-Tayyar, A. M. Youssef, and R. Al-hindi, "Antimicrobial food packaging based on sustainable bio-based materials for reducing foodborne pathogens: a review," Food Chemistry, vol. 130, Article ID 125915, 2019.

[43] A. Kalia, M. Kaur, A. Shami et al., "Nettle-Leaf extract derived $\mathrm{ZnO} / \mathrm{CuO}$ nanoparticle-biopolymer-based antioxidant and antimicrobial nanocomposite packaging films and their impact on extending the post-harvest shelf life of guava fruit," Biomolecules, vol. 11, no. 2, p. 224, 2021.

[44] N. Omerović, M. Djisalov, K. Živojević et al., "Antimicrobial nanoparticles and biodegradable polymer composites for active food packaging applications," Comprehensive Reviews in Food Science and Food Safety, vol. 20, no. 3, pp. 24282454, 2021.

[45] H. Cheng, H. Xu, D. Julian McClements et al., "Recent advances in intelligent food packaging materials: principles, preparation and applications," Food Chemistry, vol. 375, Article ID 131738, 2022.

[46] S. Pirsa, I. K. Sani, and S. S. Mirtalebi, "Nano-biocomposite based color sensors: investigation of structure, function, and applications in intelligent food packaging," Food Packaging and Shelf Life, vol. 31, Article ID 100789, 2022.

[47] M. Mesgari, A. H. Aalami, and A. Sahebkar, "Antimicrobial activities of chitosan/titanium dioxide composites as a biological nanolayer for food preservation: a review," International Journal of Biological Macromolecules, vol. 276, 2021.

[48] S. M. Emadian, T. T. Onay, and B. Demirel, "Biodegradation of bioplastics in natural environments," Waste Management, vol. 59, pp. 526-536, 2017. 
[49] A. Dey and S. Neogi, "Oxygen scavengers for food packaging applications: a Review," Trends in Food Science \& Technology, vol. 56, 2019.

[50] K. K. Gaikwad, S. Singh, and A. Ajji, "Moisture absorbers for food packaging applications," Environmental Chemistry Letters, vol. 17, no. 2, pp. 609-628, 2019.

[51] H.-G. Lee, S. Jeong, and S. Yoo, "Development of food packaging materials containing calcium hydroxide and porous medium with carbon dioxide-adsorptive function," Food Packaging and Shelf Life, vol. 21, Article ID 100352, 2019.

[52] K. Sadeghi, Y. Lee, and J. Seo, "Ethylene scavenging systems in packaging of fresh produce: a review," Food Reviews International, vol. 35, pp. 1-22, 2019.

[53] M. Flórez, E. Guerra-Rodríguez, P. Cazón, and M. Vázquez, "Chitosan for food packaging: recent advances in active and intelligent films," Food Hydrocolloids, vol. 124, Article ID 107328, 2022.

[54] A. Sultana, A. Kathuria, and K. K. Gaikwad, "Metal-organic frameworks for active food packaging," A review. Environmental Chemistry Letters.vol. 13, pp. 1-17, 2022.

[55] F. Topuz and T. Uyar, "Antioxidant, antibacterial and antifungal electrospun nanofibers for food packaging applications," Food Research International, vol. 89, Article ID 108927, 2019.

[56] T. Revathi and S. Thambidurai, "Cytotoxic, antioxidant and antibacterial activities of copper oxide incorporated chitosan-neem seed biocomposites," International Journal of Biological Macromolecules, vol. 139, pp. 867-878, 2019.

[57] D. Bharathi, R. Ranjithkumar, B. Chandarshekar, and V. Bhuvaneshwari, "Bio-inspired synthesis of chitosan/ copper oxide nanocomposite using rutin and their antiproliferative activity in human lung cancer cells," International Journal of Biological Macromolecules, vol. 141, pp. 476-483, 2019.

[58] N. Phutanon, K. Motina, Y.-H. Chang, and S. Ummartyotin, "Development of $\mathrm{CuO}$ particles onto bacterial cellulose sheets by forced hydrolysis: a synergistic approach for generating sheets with photocatalytic and antibiofouling properties," International Journal of Biological Macromolecules, vol. 136, pp. 1142-1152, 2019.

[59] H. Almasi, L. Mehryar, and A. Ghadertaj, "Characterization of $\mathrm{CuO}$-bacterial cellulose nanohybrids fabricated by in-situ and ex-situ impregnation methods," Carbohydrate Polymers, vol. 222, Article ID 114995, 2019.

[60] M. Taherimehr, H. YousefniaPasha, R. Tabatabaeekoloor, and E. Pesaranhajiabbas, "Trends and challenges of biopolymer-based nanocomposites in food packaging," Comprehensive Reviews in Food Science and Food Safety, vol. 20, no. 6, pp. 5321-5344, 2021.

[61] B. S. Sooch and M. K. Mann, "Nanoreinforced biodegradable gelatin based active food packaging film for the enhancement of shelf life of tomatoes (Solanum lycopersicum L.)," Food Control, vol. 34, Article ID 108322, 2021.

[62] Y. A. Arfat, J. Ahmed, and H. Jacob, "Preparation and characterization of agar-based nanocomposite films reinforced with bimetallic (Ag-Cu) alloy nanoparticles," Carbohydrate Polymers, vol. 155, pp. 382-390, 2017.

[63] M. Martínez-Sanz, A. Martínez-Abad, and A. López-Rubio, "Cost-efficient bio-based food packaging films from unpurified agar-based extracts," Food Packaging and Shelf Life, vol. 21, Article ID 100367, 2019.

[64] I. Malagurski, S. Levic, A. Nesic, M. Mitric, V. Pavlovic, and S. Dimitrijevic-Brankovic, "Mineralized agar-based nanocomposite films: potential food packaging materials with antimicrobial properties," Carbohydrate Polymers, vol. 175, pp. 55-62, 2017.

[65] S. Roy and J.-W. Rhim, "Preparation of pectin/agar-based functional films integrated with zinc sulfide nano petals for active packaging applications," Colloids and Surfaces B: Biointerfaces, vol. 207, Article ID 111999, 2021.

[66] M. Abdollahi, S. Damirchi, M. Shafafi, M. Rezaei, and P. Ariaii, "Carboxymethyl cellulose-agar biocomposite film activated with summer savory essential oil as an antimicrobial agent," International Journal of Biological Macromolecules, vol. 126, pp. 561-568, 2019.

[67] I. Shahabi-Ghahfarrokhi, V. Goudarzi, and A. BabaeiGhazvini, "Production of starch based biopolymer by green photochemical reaction at different UV region as a food packaging material: physicochemical characterization," International Journal of Biological Macromolecules, vol. 122, pp. 201-209, 2019.

[68] V. Goudarzi and I. Shahabi-Ghahfarrokhi, "Photo-producible and photo-degradable starch/TiO2 bionanocomposite as a food packaging material: development and characterization," International Journal of Biological Macromolecules, vol. 106, pp. 661-669, 2018.

[69] O. Rompothi, P. Pradipasena, K. Tananuwong, A. Somwangthanaroj, and T. Janjarasskul, "Development of non-water soluble, ductile mung bean starch based edible film with oxygen barrier and heat sealability," Carbohydrate Polymers, vol. 157, pp. 748-756, 2017.

[70] T. Huang, Y. Qian, J. Wei, and C. Zhou, "Polymeric antimicrobial food packaging and its applications," Polymers, vol. 11, no. 3, p. 560, 2019.

[71] O. A. Adeyeye, E. R. Sadiku, A. Babu Reddy et al., The Use of Biopolymers in Food Packaging. Green Biopolymers and Their Nanocomposites, Springer, Berlin, Germany, 2019.

[72] Y.-H. Feng, T.-Y. Cheng, W.-G. Yang et al., "Characteristics and environmentally friendly extraction of cellulose nanofibrils from sugarcane bagasse," Industrial Crops and Products, vol. 111, pp. 285-291, 2018.

[73] I. Gan and W. S. Chow, "Antimicrobial poly(lactic acid)/ cellulose bionanocomposite for food packaging application: a review," Food packaging and shelf life, vol. 17, pp. 150-161, 2018.

[74] M. Zulham Efendi Sinaga, S. Gea, N. Panindia, and Y. Alfinsyah Sihombing, "The preparation of all-cellulose nanocomposite film from isolated cellulose of corncobs as food packaging," Oriental Journal of Chemistry, vol. 34, no. 1, pp. 562-567, 2018.

[75] R. G. Candido, G. G. Godoy, and A. R. Gonçalves, "Characterization and application of cellulose acetate synthesized from sugarcane bagasse," Carbohydrate Polymers, vol. 167, pp. 280-289, 2017.

[76] M. Salari, M. Sowti Khiabani, R. Rezaei Mokarram, B. Ghanbarzadeh, and H. Samadi Kafil, "Development and evaluation of chitosan based active nanocomposite films containing bacterial cellulose nanocrystals and silver nanoparticles," Food Hydrocolloids, vol. 84, pp. 414-423, 2018.

[77] S. Ghasemi, M. R. Bari, S. Pirsa, and S. Amiri, "Use of bacterial cellulose film modified by polypyrrole/TiO2-Ag nanocomposite for detecting and measuring the growth of pathogenic bacteria," Carbohydrate Polymers, vol. 232, Article ID 115801, 2020.

[78] Y.-N. Yang, K.-Y. Lu, P. Wang, Y.-C. Ho, M.-L. Tsai, and F.-L. Mi, "Development of bacterial cellulose/chitin multi- 
nanofibers based smart films containing natural active microspheres and nanoparticles formed in situ," Carbohydrate Polymers, vol. 228, Article ID 115370, 2020.

[79] P. Díaz-Calderón, B. MacNaughtan, S. Hill, T. Foster, J. Enrione, and J. Mitchell, "Changes in gelatinisation and pasting properties of various starches (wheat, maize and waxy maize) by the addition of bacterial cellulose fibrils," Food Hydrocolloids, vol. 80, pp. 274-280, 2018.

[80] Y. Xie, X. Niu, J. Yang et al., "Active biodegradable films based on the whole potato peel incorporated with bacterial cellulose and curcumin," International Journal of Biological Macromolecules, vol. 150, pp. 480-491, 2020.

[81] Z. Liu, D. Lin, P. Lopez-Sanchez, and X. Yang, "Characterizations of bacterial cellulose nanofibers reinforced edible films based on konjac glucomannan," International Journal of Biological Macromolecules, vol. 145, pp. 634-645, 2020.

[82] P. Cazón and M. Vázquez, "Improving bacterial cellulose films by ex-situ and in-situ modifications: a review," Food Hydrocolloids, vol. 113, Article ID 106514, 2021.

[83] Z. Shi, Y. Zhang, G. O. Phillips, and G. Yang, "Utilization of bacterial cellulose in food," Food Hydrocolloids, vol. 35, pp. 539-545, 2014.

[84] S. Lu, W. Liu, Y. Wang et al., "An adsorbent based on humic acid and carboxymethyl cellulose for efficient dye removal from aqueous solution," International Journal of Biological Macromolecules, vol. 135, pp. 790-797, 2019.

[85] H. Hosseini, A. Zirakjou, D. J. McClements, V. Goodarzi, and W.-H. Chen, "Removal of methylene blue from wastewater using ternary nanocomposite aerogel systems: carboxymethyl cellulose grafted by polyacrylic acid and decorated with graphene oxide," Journal of Hazardous Materials, vol. 421, Article ID 126752, 2022.

[86] N. Tara and S. A. Chaudhry, "Polysaccharide nanocomposite materials for the removal of Methylene blue (MB) dye from water," Innovation in Nano-Polysaccharides for Eco-sustainability, vol. 185, pp. 277-295, 2022.

[87] D. Liu, Y. Dong, Y. Liu, N. Ma, and G. Sui, "Cellulose nanowhisker (CNW)/Graphene nanoplatelet (GN) composite films with simultaneously enhanced thermal, electrical and mechanical properties," Frontiers in Materials, vol. 6, p. 235, 2019.

[88] E. H. Fragal, T. S. P. Cellet, V. H. Fragal et al., "Biomimetic nanocomposite based on hydroxyapatite mineralization over chemically modified cellulose nanowhiskers: an active platform for osteoblast proliferation," International Journal of Biological Macromolecules, vol. 125, pp. 133-142, 2019.

[89] Q. Meng, A. Wang, H. Hua et al., "Intranasal delivery of Huperzine A to the brain using lactoferrin-conjugated $\mathrm{N}$-trimethylated chitosan surface-modified PLGA nanoparticles for treatment of Alzheimer's disease," International Journal of Nanomedicine, vol. 13, pp. 705-718, 2018.

[90] J. Xing, P. Tao, Z. Wu, C. Xing, X. Liao, and S. Nie, "Nanocellulose-graphene composites: a promising nanomaterial for flexible supercapacitors," Carbohydrate Polymers, vol. 207, pp. 447-459, 2019.

[91] S. Gorsse, C. Hutchinson, M. Gouné, and R. Banerjee, "Additive manufacturing of metals: a brief review of the characteristic microstructures and properties of steels, Ti$6 \mathrm{Al}-4 \mathrm{~V}$ and high-entropy alloys," Science and Technology of Advanced MaTerials, vol. 18, no. 1, pp. 584-610, 2017.

[92] A. W. Carpenter, C.-F. de Lannoy, and M. R. Wiesner, "Cellulose nanomaterials in water treatment technologies," Environmental Science and Technology, vol. 49, no. 9, pp. 5277-5287, 2015.
[93] Z. Karim, S. Claudpierre, M. Grahn, K. Oksman, and A. P. Mathew, "Nanocellulose based functional membranes for water cleaning: tailoring of mechanical properties, porosity and metal ion capture," Journal of Membrane Science, vol. 514, pp. 418-428, 2016

[94] T. A. Khattab, M. M. G. Fouda, M. Rehan et al., "Novel halochromic cellulose nanowhiskers from rice straw: visual detection of urea," Carbohydrate Polymers, vol. 231, Article ID 115740, 2020.

[95] F. Hoeng, A. Denneulin, and J. Bras, "Use of nanocellulose in printed electronics: a review," Nanoscale, vol. 8, no. 27, pp. 13131-13154, 2016.

[96] A. Serpa, J. Velásquez-Cock, P. Gañán, C. Castro, L. Vélez, and R. Zuluaga, "Vegetable nanocellulose in food science: a review," Food Hydrocolloids, vol. 57, pp. 178-186, 2016.

[97] F. Li, E. Mascheroni, and L. Piergiovanni, "The potential of nanocellulose in the packaging field: a review," Packaging Technology and Science, vol. 28, no. 6, pp. 475-508, 2015.

[98] M. Shahrousvand, M. Ghollasi, A. A. K. Zarchi, and A. Salimi, "Osteogenic differentiation of hMSCs on semiinterpenetrating polymer networks of polyurethane/pol$\mathrm{y}$ (2-hydroxyethyl methacrylate)/cellulose nanowhisker scaffolds," International Journal of Biological Macromolecules, vol. 138, pp. 262-271, 2019.

[99] M. Shamsi, M. Karimi, M. Ghollasi et al., "In vitro proliferation and differentiation of human bone marrow mesenchymal stem cells into osteoblasts on nanocomposite scaffolds based on bioactive glass $(64 \mathrm{SiO} 2-31 \mathrm{CaO}-5 \mathrm{P} 2 \mathrm{O}$ 5)-poly- 1 -lactic acid nanofibers fabricated by electrospinning method," Materials Science and Engineering: C, vol. 78, pp. 114-123, 2017.

[100] M. Shahrousvand, F. A. Tabar, E. Shahrousvand et al., "High aspect ratio phospho-calcified rock candy-like cellulose nanowhiskers of wastepaper applicable in osteogenic differentiation of hMSCs," Carbohydrate Polymers, vol. 175, pp. 293-302, 2017.

[101] D. H. Kim and Y. S. Song, "Anisotropic optical film embedded with cellulose nanowhisker," Carbohydrate Polymers, vol. 130, pp. 448-454, 2015.

[102] C. Xu, J. Chen, D. Wu, Y. Chen, Q. Lv, and M. Wang, "Polylactide/acetylated nanocrystalline cellulose composites prepared by a continuous route: a phase interface-property relation study," Carbohydrate Polymers, vol. 146, pp. 58-66, 2016.

[103] J.-H. Kim, B. S. Shim, H. S. Kim et al., "Review of nanocellulose for sustainable future materials," International Journal of Precision Engineering and Manufacturing-Green Technology, vol. 2, no. 2, pp. 197-213, 2015.

[104] L.-F. Wang, S. Shankar, and J.-W. Rhim, "Properties of alginate-based films reinforced with cellulose fibers and cellulose nanowhiskers isolated from mulberry pulp," Food Hydrocolloids, vol. 63, pp. 201-208, 2017.

[105] M. Perini, T. Nardin, M. Venturelli, S. Pianezze, and R. Larcher, "Stable isotope ratio analysis as a fast and simple method for identifying the origin of chitosan," Food $\mathrm{Hy}$ drocolloids, vol. 101, p. 105516, 2020.

[106] P. Fernandez-Saiz, "Chitosan polysaccharide in food packaging applications," Multifunctional and Nanoreinforced Polymers for Food Packaging, vol. 10, pp. 571-593, 2011.

[107] M. Pereda, G. Amica, and N. E. Marcovich, "Development and characterization of edible chitosan/olive oil emulsion films," Carbohydrate Polymers, vol. 87, no. 2, pp. 1318-1325, 2012. 
[108] M. Z. Elsabee and E. S. Abdou, "Chitosan based edible films and coatings: a review," Materials Science and Engineering: C, vol. 33, no. 4, pp. 1819-1841, 2013.

[109] I. Leceta, P. Guerrero, and K. De la Caba, "Functional properties of chitosan-based films," Carbohydrate Polymers, vol. 93, no. 1, pp. 339-346, 2013.

[110] G. López-Carballo, J. Gomez-Estaca, R. Catala, P. Hernández-Muñoz, and R. Gavara, Active Antimicrobial Food and Beverage packaging. Emerging Food Packaging Technologies, pp. 27-54, Elsevier, Amsterdam, Netherlands, 2012.

[111] U. Garg, S. Chauhan, U. Nagaich, and N. Jain, "Current advances in chitosan nanoparticles based drug delivery and targeting," Advanced Pharmaceutical Bulletin, vol. 9, no. 2, pp. 195-204, 2019.

[112] L. F. Zemljič, T. Tkavc, A. Vesel, and O. Šauperl, “Chitosan coatings onto polyethylene terephthalate for the development of potential active packaging material," Applied Surface Science, vol. 265, pp. 697-703, 2013.

[113] E. Assanti, V. K. Karabagias, I. K. Karabagias, A. Badeka, and M. G. Kontominas, "Shelf life evaluation of fresh chicken burgers based on the combination of chitosan dip and vacuum packaging under refrigerated storage," Journal of Food Science \& Technology, vol. 58, no. 3, pp. 870-883, 2021.

[114] G. Mustăţea, E. L. Ungureanu, and N. Belc, "Polylactic acid (pla) for food packaging applications-a short overview," Annals: Food Science \& Technology (New York), vol. 20, no. 1, pp. 9-14, 2019.

[115] C. Sun, M. Yu, Z. Zeng, F. Francis, H. Cui, and F. Verheggen, "Biocidal activity of polylactic acid-based nano-formulated abamectin on Acyrthosiphon pisum (Hemiptera: aphididae) and the aphid predator Adalia bipunctata (Coleoptera: coccinellidae)," PLoS One, vol. 15, no. 2, Article ID e0228817, 2020.

[116] N. Hashim, K. Retenam, S. Somderam, and K. Yusoh, Eds., Advanced Materials ResearchTrans Tech Publ, Zurich, Switzerland, 2016.

[117] K. K. Gaikwad, S. Singh, and Y. S. Lee, "Oxygen scavenging films in food packaging," Environmental Chemistry Letters, vol. 16, no. 2, pp. 523-538, 2018.

[118] X. He, T. Dai, J. Sun et al., "Effective change on rheology and structure properties of xanthan gum by industry-scale microfluidization treatment," Food Hydrocolloids, vol. 124, Article ID 107319, 2022.

[119] E. Ramos de Souza, P. D. Rodrigues, I. C. F. Sampaio et al., "Xanthan gum produced by Xanthomonas campestris using produced water and crude glycerin as an environmentally friendlier agent to enhance oil recovery," Fuel, vol. 310, Article ID 122421, 2022.

[120] R. Baruah, K. Rajshee, and P. M. Halami, "Exopolysaccharide producing microorganisms for functional food industry," Current Developments in Biotechnology and Bioengineering, vol. 89, pp. 337-354, 2022.

[121] S. Yuan, J. Liang, Y. Zhang et al., "Evidence from thermal aging indicating that the synergistic effect of glyoxal and sodium sulfite improved the thermal stability of conformational modified xanthan gum," Polymers, vol. 14, no. 2, p. 243, 2022.

[122] R. Balasubramanian, S. S. Kim, J. Lee, and J. Lee, "Effect of $\mathrm{TiO} 2$ on highly elastic, stretchable UV protective nanocomposite films formed by using a combination of k-Carrageenan, xanthan gum and gellan gum," International Journal of Biological Macromolecules, vol. 123, pp. 10201027, 2019.
[123] B. Rukmanikrishnan, S. K. Rajasekharan, J. Lee, and J. Lee, "Biocompatible agar/xanthan gum composite films: thermal, mechanical, UV, and water barrier properties," Polymers for Advanced Technologies, vol. 30, no. 11, pp. 2750-2758, 2019.

[124] B. Sujithra, S. Deepika, K. Akshaya, and V. Ponnusami, "Production and optimization of xanthan gum from threestep sequential enzyme treated cassava bagasse hydrolysate," Biocatalysis and Agricultural Biotechnology, vol. 21, Article ID 101294, 2019.

[125] R. F. Li, P. Cui, P. Z. Wei, X. Y. Liu, J. L. Tang, and G. T. Lu, "HprKXccis a serine kinase that regulates virulence in the Gram-negative phytopathogenXanthomonas campestris," Environmental Microbiology, vol. 21, no. 12, pp. 4504-4520, 2019.

[126] M. Sapper, P. Talens, and A. Chiralt, "Improving functional properties of cassava starch-based films by incorporating xanthan, gellan, or pullulan gums," International Journal of Polymer Science, vol. 2019, Article ID 5367164, 11 pages, 2019.

[127] M. A. S. P. Nur Hazirah, M. I. N. Isa, and N. M. Sarbon, "Effect of xanthan gum on the physical and mechanical properties of gelatin-carboxymethyl cellulose film blends," Food Packaging and Shelf Life, vol. 9, pp. 55-63, 2016.

[128] Y. Du, J. Sun, L. Wang et al., "Development of antimicrobial packaging materials by incorporation of gallic acid into $\mathrm{Ca} 2+$ crosslinking konjac glucomannan/gellan gum films," International Journal of Biological Macromolecules, vol. 137, pp. 1076-1085, 2019.

[129] Y.-C. Wei, C.-H. Cheng, Y.-C. Ho, M.-L. Tsai, and F.-L. Mi, "Active gellan gum/purple sweet potato composite films capable of monitoring $\mathrm{pH}$ variations," Food Hydrocolloids, vol. 69, pp. 491-502, 2017.

[130] M. W. Rahman and M. T. Arafat, "Gellan and xanthan-based nanocomposites for tissue engineering," PolysaccharideBased Nanocomposites for Gene Delivery and Tissue Engineering, vol. 46, pp. 155-190, 2021.

[131] R. Balasubramanian, S. S. Kim, and J. Lee, "Novel synergistic transparent k-Carrageenan/Xanthan gum/Gellan gum hydrogel film: mechanical, thermal and water barrier properties," International Journal of Biological Macromolecules, vol. 118, pp. 561-568, 2018.

[132] M. A. Bonifacio, P. Gentile, A. M. Ferreira, S. Cometa, and E. De Giglio, "Insight into halloysite nanotubes-loaded gellan gum hydrogels for soft tissue engineering applications," Carbohydrate Polymers, vol. 163, pp. 280-291, 2017.

[133] H. Lee, B. Rukmanikrishnan, and J. Lee, "Rheological, morphological, mechanical, and water-barrier properties of agar/gellan gum/montmorillonite clay composite films," International Journal of Biological Macromolecules, vol. 141, pp. 538-544, 2019.

[134] B. Kundu, V. Brancato, J. Oliveira, V. M. Correlo, R. L. Reis, and S. Kundu, "Silk fibroin promotes mineralization of gellan gum hydrogels," International Journal of Biological Macromolecules, vol. 14, 2019.

[135] B. Rukmanikrishnan, F. R. M. Ismail, R. K. Manoharan, S. S. Kim, and J. Lee, "Blends of gellan gum/xanthan gum/ zinc oxide based nanocomposites for packaging application: rheological and antimicrobial properties," International Journal of Biological Macromolecules, vol. 35, 2019.

[136] S. M. Kuo, S. J. Chang, H.-Y. Wang, S. C. Tang, and S.-W. Yang, "Evaluation of the ability of xanthan gum/gellan gum/hyaluronan hydrogel membranes to prevent the adhesion of postrepaired tendons," Carbohydrate Polymers, vol. 114, pp. 230-237, 2014. 
[137] L. Abolghasemi Fakhri, B. Ghanbarzadeh, J. Dehghannya, F. Abbasi, and H. Ranjbar, "Optimization of mechanical and color properties of polystyrene/nanoclay/nano $\mathrm{ZnO}$ based nanocomposite packaging sheet using response surface methodology," Food packaging and shelf life, vol. 17, pp. 11-24, 2018.

[138] P. Kanmani and J.-W. Rhim, "Properties and characterization of bionanocomposite films prepared with various biopolymers and $\mathrm{ZnO}$ nanoparticles," Carbohydrate Polymers, vol. 106, pp. 190-199, 2014.

[139] N. Noshirvani, B. Ghanbarzadeh, R. R. Mokarram, M. Hashemi, and V. Coma, "Preparation and characterization of active emulsified films based on chitosan-carboxymethyl cellulose containing zinc oxide nano particles," International Journal of Biological Macromolecules, vol. 99, pp. 530-538, 2017.

[140] M. Zolfi, F. Khodaiyan, M. Mousavi, and M. Hashemi, "Development and characterization of the kefiran-whey protein isolate-TiO2 nanocomposite films," International Journal of Biological Macromolecules, vol. 65, pp. 340-345, 2014.

[141] A. M. El Sayed, S. El-Gamal, W. M. Morsi, and G. Mohammed, "Effect of PVA and copper oxide nanoparticles on the structural, optical, and electrical properties of carboxymethyl cellulose films," Journal of Materials Science, vol. 50, no. 13, pp. 4717-4728, 2015.

[142] S. Shankar, L.-F. Wang, and J.-W. Rhim, "Preparation and properties of carbohydrate-based composite films incorporated with $\mathrm{CuO}$ nanoparticles," Carbohydrate Polymers, vol. 169, pp. 264-271, 2017.

[143] S. Shankar and J.-W. Rhim, "Effect of copper salts and reducing agents on characteristics and antimicrobial activity of copper nanoparticles," Materials Letters, vol. 132, pp. 307311, 2014.

[144] A. Conte, D. Longano, C. Costa et al., "A novel preservation technique applied to fiordilatte cheese," Innovative Food Science \& Emerging Technologies, vol. 19, pp. 158-165, 2013.

[145] I. M. Araújo, R. R. Silva, G. Pacheco, W. R. Lustri, A. Tercjak, and J. Gutierrez, "Hydrothermal synthesis of bacterial cellulose-copper oxide nanocomposites and evaluation of their antimicrobial activity," Carbohydrate Polymers, vol. 179, pp. 341-349, 2018.

[146] Y. Xiao, L. Rong, B. Wang et al., "A light-weight and highefficacy antibacterial nanocellulose-based sponge via covalent immobilization of gentamicin," Carbohydrate Polymers, vol. 200, pp. 595-601, 2018.

[147] M. Yadollahi, I. Gholamali, H. Namazi, and M. Aghazadeh, "Synthesis and characterization of antibacterial carboxymethylcellulose/CuO bio-nanocomposite hydrogels," International Journal of Biological Macromolecules, vol. 73, pp. 109-114, 2015.

[148] S. Farhoudian, M. Yadollahi, and H. Namazi, "Facile synthesis of antibacterial chitosan/CuO bio-nanocomposite hydrogel beads," International Journal of Biological Macromolecules, vol. 82, pp. 837-843, 2016.

[149] K. Saravanakumar, A. Sathiyaseelan, A. V. A. Mariadoss, H. Xiaowen, and M.-H. Wang, "Physical and bioactivities of biopolymeric films incorporated with cellulose, sodium alginate and copper oxide nanoparticles for food packaging application," International Journal of Biological Macromolecules, vol. 67, 2020.

[150] L. E. Nielsen and R. Landel, Mechanical Properties of Polymers and Composites, Marcel Dekker, New York, NY, USA, 1994.
[151] S. Shankar, N. Tanomrod, S. Rawdkuen, and J.-W. Rhim, "Preparation of pectin/silver nanoparticles composite films with UV-light barrier and properties," International Journal of Biological Macromolecules, vol. 92, pp. 842-849, 2016.

[152] K. K. Sadasivuni, P. Saha, J. Adhikari, K. Deshmukh, M. B. Ahamed, and J. J. Cabibihan, "Recent advances in mechanical properties of biopolymer composites: a review," Polymer Composites, vol. 121, 2019.

[153] R. A. Ilyas, S. M. Sapuan, M. R. Ishak, and E. S. Zainudin, "Development and characterization of sugar palm nanocrystalline cellulose reinforced sugar palm starch bionanocomposites," Carbohydrate Polymers, vol. 202, pp. 186-202, 2018.

[154] M. Halimatul, S. Sapuan, M. Jawaid, M. Ishak, and R. Ilyas, "Effect of sago starch and plasticizer content on the properties of thermoplastic films: mechanical testing and cyclic soaking-drying," Polimery, vol. 64, no. 6, 2019.

[155] A. George, M. Sanjay, R. Sriusk, J. Parameswaranpillai, and S. Siengchin, "A comprehensive review on chemical properties and applications of biopolymers and their composites," International Journal of Biological Macromolecules, vol. 98, 2020.

[156] R. A. Ilyas, S. M. Sapuan, and M. R. Ishak, "Isolation and characterization of nanocrystalline cellulose from sugar palm fibres (Arenga Pinnata)," Carbohydrate Polymers, vol. 181, pp. 1038-1051, 2018.

[157] A. Shahzad, "Mechanical properties of eco-friendly polymer nanocomposites," in Eco-Friendly Polymer Nanocomposites, pp. 527-559, Springer, Berlin, Germany, 2015.

[158] M. John and S. Thomas, "Biofibres and biocomposites," Carbohydrate Polymers, vol. 71, no. 3, pp. 343-364, 2008.

[159] S. J. Peighambardoust, S. H. Peighambardoust, N. Pournasir, and P. Mohammadzadeh Pakdel, "Properties of active starch-based films incorporating a combination of $\mathrm{Ag}, \mathrm{ZnO}$ and $\mathrm{CuO}$ nanoparticles for potential use in food packaging applications," Food Packaging and Shelf Life, vol. 22, Article ID 100420, 2019.

[160] C. Vasile, M. Râpă, M. Ştefan, M. Stan, S. Macavei, and R. Darie-Niţă, "New PLA/ZnO: Cu/Ag bionanocomposites for food packaging," Express Polymer Letters, vol. 11, no. 7, 2017.

[161] G. Mary, S. K. Bajpai, and N. Chand, "Copper (II) ions and copper nanoparticles-loaded chemically modified cotton cellulose fibers with fair antibacterial properties," Journal of Applied Polymer Science, vol. 113, no. 2, pp. 757-766, 2009.

[162] G. Cárdenas, M. Meléndrez, and A. G. Cancino, "Colloidal $\mathrm{Cu}$ nanoparticles/chitosan composite film obtained by microwave heating for food package applications," Polymer Bulletin, vol. 62, no. 4, pp. 511-524, 2009.

[163] S.-M. Hasheminya, R. Rezaei Mokarram, B. Ghanbarzadeh, H. Hamishekar, and H. S. Kafil, "Physicochemical, mechanical, optical, microstructural and antimicrobial properties of novel kefiran-carboxymethyl cellulose biocomposite films as influenced by copper oxide nanoparticles (CuONPs)," Food packaging and shelf life, vol. 17, pp. 196204, 2018.

[164] H. Chambi and C. Grosso, "Edible films produced with gelatin and casein cross-linked with transglutaminase," Food Research International, vol. 39, no. 4, pp. 458-466, 2006.

[165] A. Babaei-Ghazvini, I. Shahabi-Ghahfarrokhi, and V. Goudarzi, "Preparation of UV-protective starch/kefiran/ $\mathrm{ZnO}$ nanocomposite as a packaging film: Characterization," Food packaging and shelf life, vol. 16, pp. 103-111, 2018. 
[166] J. Ahmed, Y. A. Arfat, E. Castro-Aguirre, and R. Auras, "Mechanical, structural and thermal properties of $\mathrm{Ag}-\mathrm{Cu}$ and $\mathrm{ZnO}$ reinforced polylactide nanocomposite films," International Journal of Biological Macromolecules, vol. 86, pp. 885-892, 2016.

[167] J. Jayaramudu, K. Das, M. Sonakshi et al., "Structure and properties of highly toughened biodegradable polylactide/ ZnO biocomposite films," International Journal of Biological Macromolecules, vol. 64, pp. 428-434, 2014.

[168] L.-T. Lim, R. Auras, and M. Rubino, "Processing technologies for poly(lactic acid)," Progress in Polymer Science, vol. 33, no. 8, pp. 820-852, 2008.

[169] A. Shrivastava, Introduction to Plastics Engineering, William Andrew, Amsterdam, Netherlands, 2018.

[170] ISO. Plastics-Differential Scanning Calorimetry (DSC), "Part 2: determination of glass transition temperature," 1999.

[171] X. H. Li, Y. G. Xing, W. L. Li, Y. H. Jiang, and Y. L. Ding, "Antibacterial and physical properties of poly(vinyl chloride)-based film coated with $\mathrm{ZnO}$ nanoparticles," Food Science and Technology International, vol. 16, no. 3, pp. 225-232, 2010.

[172] A. A. Oun and J.-W. Rhim, "Carrageenan-based hydrogels and films: effect of $\mathrm{ZnO}$ and $\mathrm{CuO}$ nanoparticles on the physical, mechanical, and antimicrobial properties," Food Hydrocolloids, vol. 67, pp. 45-53, 2017.

[173] S. M. Ojagh, M. Rezaei, S. H. Razavi, and S. M. H. Hosseini, "Development and evaluation of a novel biodegradable film made from chitosan and cinnamon essential oil with low affinity toward water," Food Chemistry, vol. 122, no. 1, pp. 161-166, 2010.

[174] J.-W. Rhim, L.-F. Wang, Y. Lee, and S.-I. Hong, "Preparation and characterization of bio-nanocomposite films of agar and silver nanoparticles: laser ablation method," Carbohydrate Polymers, vol. 103, pp. 456-465, 2014.

[175] J. K. Rao, A. Raizada, D. Ganguly, M. M. Mankad, S. V. Satyanarayana, and G. M. Madhu, "Enhanced mechanical properties of polyvinyl alcohol composite films containing copper oxide nanoparticles as filler," Polymer Bulletin, vol. 72, no. 8, pp. 2033-2047, 2015.

[176] A. H. Bedane, M. Eić, M. Farmahini-Farahani, and H. Xiao, "Water vapor transport properties of regenerated cellulose and nanofibrillated cellulose films," Journal of Membrane Science, vol. 493, pp. 46-57, 2015.

[177] J. F. Rubilar, R. N. Zúñiga, F. Osorio, and F. Pedreschi, "Physical properties of emulsion-based hydroxypropyl methylcellulose/whey protein isolate (HPMC/WPI) edible films," Carbohydrate Polymers, vol. 123, pp. 27-38, 2015.

[178] V. Siracusa, P. Rocculi, S. Romani, and M. D. Rosa, "Biodegradable polymers for food packaging: a review," Trends in Food Science \& Technology, vol. 19, no. 12, pp. 634-643, 2008.

[179] P. Cazón, G. Velazquez, J. A. Ramírez, and M. Vázquez, "Polysaccharide-based films and coatings for food packaging: a review," Food Hydrocolloids, vol. 68, pp. 136-148, 2017.

[180] S. Dagnas, M. Gougouli, B. Onno, K. P. Koutsoumanis, and J.-M. Membré, "Quantifying the effect of water activity and storage temperature on single spore lag times of three moulds isolated from spoiled bakery products," International Journal of Food Microbiology, vol. 240, pp. 75-84, 2017.

[181] M. Joshi, B. Adak, and B. S. Butola, "Polyurethane nanocomposite based gas barrier films, membranes and coatings: a review on synthesis, characterization and potential applications," Progress in Materials Science, vol. 97, pp. 230$282,2018$.
[182] C. Rovera, M. Ghaani, and S. Farris, "Nano-inspired oxygen barrier coatings for food packaging applications: an overview," Trends in Food Science \& Technology, vol. 203, 2020.

[183] A. Katayama-Ikegami, Y. Suehiro, T. Katayama, K. Jindo, H. Itamura, and T. Esumi, "Recombinant expression, purification, and characterization of polyphenol oxidase 2 (VvPPO2) from "Shine Muscat" (Vitis labruscana Bailey $\times$ Vitis vinifera L.)," Bioscience Biotechnology and Biochemistry, vol. 81, no. 12, pp. 2330-2338, 2017.

[184] J. A. Daniels, R. Krishnamurthi, and S. S. H. Rizvi, “A review of effects of carbon dioxide on microbial growth and food quality," Journal of Food Protection, vol. 48, no. 6, pp. 532-537, 1985.

[185] P. Puligundla, J. Jung, and S. Ko, "Carbon dioxide sensors for intelligent food packaging applications," Food Control, vol. 25, no. 1, pp. 328-333, 2012.

[186] J. Yu, J. Yang, B. Liu, and X. Ma, "Preparation and characterization of glycerol plasticized-pea starch/ZnO-carboxymethylcellulose sodium nanocomposites," Bioresource Technology, vol. 100, no. 11, pp. 2832-2841, 2009.

[187] Y. A. Arfat, M. Ejaz, H. Jacob, and J. Ahmed, "Deciphering the potential of guar gum/Ag-Cu nanocomposite films as an active food packaging material," Carbohydrate Polymers, vol. 157, pp. 65-71, 2017.

[188] Y. Haldorai and J.-J. Shim, "Multifunctional chitosan-copper oxide hybrid material: photocatalytic and antibacterial activities," International Journal of Photoenergy, vol. 2013, 2013.

[189] S. K. Bajpai, N. Chand, and V. Chaurasia, "Investigation of water vapor permeability and antimicrobial property of zinc oxide nanoparticles-loaded chitosan-based edible film," Journal of Applied Polymer Science, vol. 115, no. 2, pp. 674-683, 2010.

[190] X. Ma, P. R. Chang, J. Yang, and J. Yu, "Preparation and properties of glycerol plasticized-pea starch/zinc oxidestarch bionanocomposites," Carbohydrate Polymers, vol. 75, no. 3, pp. 472-478, 2009.

[191] P. J. P. Espitia, N. D. F. F. Soares, R. F. Teófilo et al., "Physical-mechanical and antimicrobial properties of nanocomposite films with pediocin and $\mathrm{ZnO}$ nanoparticles," Carbohydrate Polymers, vol. 94, no. 1, pp. 199-208, 2013.

[192] H. Hashemi Gahruie and M. Niakousari, "Antioxidant, antimicrobial, cell viability and enzymatic inhibitory of antioxidant polymers as biological macromolecules," International Journal of Biological Macromolecules, vol. 104, pp. 606-617, 2017.

[193] C. López de Dicastillo, F. Rodríguez, A. Guarda, and M. J. Galotto, "Antioxidant films based on cross-linked methyl cellulose and native Chilean berry for food packaging applications," Carbohydrate Polymers, vol. 136, pp. 10521060, 2016.

[194] E. M. Powers and D. Berkowitz, "Efficacy of an oxygen scavenger to modify the atmosphere and prevent mold growth on meal, ready-to-eat pouched bread," Journal of Food Protection, vol. 53, no. 9, pp. 767-771, 1990.

[195] S. A. Hogan and J. P. Kerry, "Smart packaging of meat and poultry products," Smart Packaging Technologies for Fast Moving Consumer Goods, vol. 93, pp. 33-59, 2013.

[196] D. Munteanu and C. Csunderlik, "Polyethylene-bound antioxidants," Polymer Degradation and Stability, vol. 34, no. 13, pp. 295-307, 1991.

[197] S. Al-Malaika, "Mechanisms of antioxidant action and stabilisation technology-the Aston experience," Polymer Degradation and Stability, vol. 34, no. 1-3, pp. 1-36, 1991. 
[198] J.-W. Han, L. Ruiz-Garcia, J.-P. Qian, and X.-T. Yang, "Food packaging: a comprehensive review and future trends," Comprehensive Reviews in Food Science and Food Safety, vol. 17, no. 4, pp. 860-877, 2018.

[199] J. Gómez-Estaca, C. López-de-Dicastillo, P. HernándezMuñoz, R. Catalá, and R. Gavara, "Advances in antioxidant active food packaging," Trends in Food Science \& Technology, vol. 35, no. 1, pp. 42-51, 2014.

[200] D. Rehana, D. Mahendiran, R. S. Kumar, and A. K. Rahiman, "Evaluation of antioxidant and anticancer activity of copper oxide nanoparticles synthesized using medicinally important plant extracts," Biomedicine \& Pharmacotherapy, vol. 89, pp. 1067-1077, 2017.

[201] L. Muthulakshmi, N. Rajini, H. Nellaiah, T. Kathiresan, M. Jawaid, and A. V. Rajulu, "Preparation and properties of cellulose nanocomposite films with in situ generated copper nanoparticles using Terminalia catappa leaf extract," International Journal of Biological Macromolecules, vol. 95, pp. 1064-1071, 2017.

[202] T. Jayaramudu, K. Varaprasad, R. D. Pyarasani et al., "Chitosan capped copper oxide/copper nanoparticles encapsulated microbial resistant nanocomposite films," International Journal of Biological Macromolecules, vol. 128, pp. 499-508, 2019.

[203] H. R. Ashjari, M. S. S. Dorraji, V. Fakhrzadeh et al., "Starchbased polyurethane/CuO nanocomposite foam: antibacterial effects for infection control," International Journal of Biological Macromolecules, vol. 111, pp. 1076-1082, 2018.

[204] F. Wahid, H.-S. Wang, Y.-S. Lu, C. Zhong, and L.-Q. Chu, "Preparation, characterization and antibacterial applications of carboxymethyl chitosan/CuO nanocomposite hydrogels," International Journal of Biological Macromolecules, vol. 101, pp. 690-695, 2017.

[205] A. M. Al-Enizi, T. Ahamad, A. B. Al-Hajji, J. Ahmed, A. A. Chaudhary, and S. M. Alshehri, "Cellulose gum and copper nanoparticles based hydrogel as antimicrobial agents against urinary tract infection (UTI) pathogens," International Journal of Biological Macromolecules, vol. 109, pp. 803-809, 2018.

[206] P. Naderi Asrami, S. A. Mozaffari, M. Saber Tehrani, and P. Aberoomand Azar, "A novel impedimetric glucose biosensor based on immobilized glucose oxidase on a $\mathrm{CuO}$ Chitosan nanobiocomposite modified FTO electrode," International Journal of Biological Macromolecules, vol. 118, pp. 649-660, 2018.

[207] G. L. Vanti, S. Masaphy, M. Kurjogi, S. Chakrasali, and V. B. Nargund, "Synthesis and application of chitosancopper nanoparticles on damping off causing plant pathogenic fungi," International Journal of Biological Macromolecules, vol. 154, 2019.

[208] L. Muthulakshmi, A. Varada Rajalu, G. S. Kaliaraj, S. Siengchin, J. Parameswaranpillai, and R. Saraswathi, "Preparation of cellulose/copper nanoparticles bionanocomposite films using a bioflocculant polymer as reducing agent for antibacterial and anticorrosion applications," Composites Part B: Engineering, vol. 175, Article ID 107177, 2019.

[209] T. Kamal, "Aminophenols formation from nitrophenols using agar biopolymer hydrogel supported $\mathrm{CuO}$ nanoparticles catalyst," Polymer Testing, vol. 77, Article ID 105896, 2019.

[210] S. Logpriya, V. Bhuvaneshwari, D. Vaidehi, R. P. SenthilKumar, and R. S. Nithya Malar, "Preparation and characterization of ascorbic acid-mediated chitosan- copper oxide nanocomposite for anti-microbial, sporicidal and biofilm-inhibitory activity," Journal of Nanostructure in Chemistry, vol. 8, no. 3, pp. 301-309, 2018.

[211] A. Wan, Q. Xu, Y. Sun, and H. Li, "Antioxidant activity of high molecular weight chitosan and N,O-quaternized chitosans," Journal of Agricultural and Food Chemistry, vol. 61, no. 28, pp. 6921-6928, 2013.

[212] S. Omidi and A. Kakanejadifard, "Modification of chitosan and chitosan nanoparticle by long chain pyridinium compounds: synthesis, characterization, antibacterial, and antioxidant activities," Carbohydrate Polymers, vol. 208, pp. 477-485, 2019.

[213] P. Criado, C. Fraschini, S. Salmieri, D. Becher, A. Safrany, and M. Lacroix, "Evaluation of antioxidant cellulose nanocrystals and applications in gellan gum films," Industrial Biotechnology, vol. 11, no. 1, pp. 59-68, 2015.

[214] T. H. Tran and V. T. Nguyen, "Copper oxide nanomaterials prepared by solution methods, some properties, and potential applications: a brief review," International scholarly research notices, vol. 2014, Article ID 856592, 2014.

[215] M. S. Jadhav, S. Kulkarni, P. Raikar, D. A. Barretto, S. K. Vootla, and U. S. Raikar, "Green biosynthesis of $\mathrm{CuO} \&$ $\mathrm{Ag}-\mathrm{CuO}$ nanoparticles from Malus domestica leaf extract and evaluation of antibacterial, antioxidant and DNA cleavage activities," New Journal of Chemistry, vol. 42, no. 1, pp. 204-213, 2018.

[216] C. Goodburn and C. A. Wallace, "The microbiological efficacy of decontamination methodologies for fresh produce: a review," Food Control, vol. 32, no. 2, pp. 418-427, 2013.

[217] M. Vanderroost, P. Ragaert, F. Devlieghere, and B. De Meulenaer, "Intelligent food packaging: the next generation," Trends in Food Science \& Technology, vol. 39, no. 1, pp. 47-62, 2014.

[218] A. Mousavi Khaneghah, S. M. B. Hashemi, and S. Limbo, "Antimicrobial agents and packaging systems in antimicrobial active food packaging: an overview of approaches and interactions," Food and Bioproducts Processing, vol. 111, pp. 1-19, 2018.

[219] A. S. Abreu, M. Oliveira, A. de Sá et al., "Antimicrobial nanostructured starch based films for packaging," Carbohydrate Polymers, vol. 129, pp. 127-134, 2015.

[220] L. Tamayo, M. Azócar, M. Kogan, A. Riveros, and M. Páez, "Copper-polymer nanocomposites: an excellent and costeffective biocide for use on antibacterial surfaces," Materials Science and Engineering: C, vol. 69, pp. 1391-1409, 2016.

[221] J. Quesada, E. Sendra, C. Navarro, and E. Sayas-Barberá, "Antimicrobial active packaging including chitosan films with Thymus vulgaris L. essential oil for ready-to-eat meat," Foods, vol. 5, no. 3, p. 57, 2016.

[222] M. Duran, M. S. Aday, N. N. D. Zorba, R. Temizkan, M. B. Büyükcan, and C. Caner, "Potential of antimicrobial active packaging 'containing natamycin, nisin, pomegranate and grape seed extract in chitosan coating' to extend shelf life of fresh strawberry," Food and Bioproducts Processing, vol. 98, pp. 354-363, 2016.

[223] D. Dehnad, H. Mirzaei, Z. Emam-Djomeh, S.-M. Jafari, and S. Dadashi, "Thermal and antimicrobial properties of chitosan-nanocellulose films for extending shelf life of ground meat," Carbohydrate Polymers, vol. 109, pp. 148-154, 2014.

[224] S. M. Jafari, I. Bahrami, D. Dehnad, and S. A. Shahidi, "The influence of nanocellulose coating on saffron quality during storage," Carbohydrate Polymers, vol. 181, pp. 536-542, 2018.

[225] M. Carbone, D. T. Donia, G. Sabbatella, and R. Antiochia, "Silver nanoparticles in polymeric matrices for fresh food 
packaging," Journal of King Saud University Science, vol. 28, no. 4, pp. 273-279, 2016.

[226] D. Marković, H.-H. Tseng, T. Nunney, M. Radoičić, T. IlicTomic, and M. Radetić, "Novel antimicrobial nanocomposite based on polypropylene non-woven fabric, biopolymer alginate and copper oxides nanoparticles," Applied Surface Science, vol. 527, Article ID 146829, 2020.

[227] S. Jiang, F. Wang, X. Cao et al., "Novel application of ion exchange membranes for preparing effective silver and copper based antibacterial membranes," Chemosphere, vol. 287, Article ID 132131, 2022.

[228] G. M. Raghavendra, J. Jung, D. Kim, and J. Seo, "Chitosanmediated synthesis of flowery-CuO, and its antibacterial and catalytic properties," Carbohydrate Polymers, vol. 172, pp. 78-84, 2017.

[229] K. Delgado, R. Quijada, R. Palma, and H. Palza, "Polypropylene with embedded copper metal or copper oxide nanoparticles as a novel plastic antimicrobial agent," Letters in Applied Microbiology, vol. 53, no. 1, pp. 50-54, 2011.

[230] A. Satyvaldiev, Z. Zhasnakunov, E. Omurzak, T. Doolotkeldieva, S. Bobusheva, and G. Orozmatova, "Copper nanoparticles: synthesis and biological activity," IOP Conference Series: Materials Science and Engineering, IOP Publishing, Bristol, UK, 2018.

[231] N. Cioffi, L. Torsi, N. Ditaranto et al., "Copper nanoparticle/ polymer composites with antifungal and bacteriostatic properties," Chemistry of Materials, vol. 17, no. 21, pp. 5255-5262, 2005.

[232] A. J. Varma, S. V. Deshpande, and J. F. Kennedy, "Metal complexation by chitosan and its derivatives: a review," Carbohydrate Polymers, vol. 55, no. 1, pp. 77-93, 2004. 